NBER WORKING PAPER SERIES

\title{
THE IMPACT OF ALCOHOL ON MENTAL HEALTH, PHYSICAL FITNESS, AND JOB PERFORMANCE
}

\author{
Marigee Bacolod \\ Jesse M. Cunha \\ Yu-Chu Shen \\ Working Paper 23542 \\ http://www.nber.org/papers/w23542 \\ NATIONAL BUREAU OF ECONOMIC RESEARCH \\ 1050 Massachusetts Avenue \\ Cambridge, MA 02138 \\ June 2017
}

We thank Jeremy Arkes for helpful comments. Any opinions, findings, and conclusions or recommendations expressed in this material are those of the authors and do not necessarily reflect the views of the Departments of the Navy or Defense, or the National Bureau of Economic Research.

NBER working papers are circulated for discussion and comment purposes. They have not been peer-reviewed or been subject to the review by the NBER Board of Directors that accompanies official NBER publications.

(C) 2017 by Marigee Bacolod, Jesse M. Cunha, and Yu-Chu Shen. All rights reserved. Short sections of text, not to exceed two paragraphs, may be quoted without explicit permission provided that full credit, including $(\odot$ notice, is given to the source. 
The Impact of Alcohol on Mental Health, Physical Fitness, and Job Performance Marigee Bacolod, Jesse M. Cunha, and Yu-Chu Shen

NBER Working Paper No. 23542

June 2017

JEL No. I1,I12

\begin{abstract}
$\underline{\text { ABSTRACT }}$
We study the impact of legal access to alcohol on a range of behavioral and physical outcomes of U.S. Army soldiers in a regression discontinuity design. The wealth of novel data collected by the military on cognitive ability, psychological health, and family history allows us to explore how impacts vary with risk factors for alcohol consumption. Overall, we observe a large and significant increase in drinking after the 21st birthday, but the increases are largest amongst those who were depressed, had a family history of mental health problems, had better coping ability, and had higher cognitive ability. Despite the large increase in consumption, we do not find any meaningful impacts of legal access to alcohol - overall or in any sub-group - on any of the shortterm outcomes we observe, including suicidal tendencies, depression, tobacco use, physical fitness, psychological health, deployability, smoking, and job-related infractions. Acknowledging the limitations for extrapolation out of sample, we discuss the policy implications of our results.

Marigee Bacolod

Graduate School of Business and Public Policy

Naval Postgraduate School

Monterey CA 93943

mbacolod@nps.edu

Jesse M. Cunha

Naval Postgraduate School

Graduate School of Business

and Public Policy

555 Dyer Rd

Monterey, CA 93943

jcunha@nps.edu

Yu-Chu Shen

Graduate School of Business and Public Policy Naval Postgraduate School

555 Dyer Road

Monterey, CA 93943

and NBER

yshen@nps.edu
\end{abstract}




\section{Introduction}

Alcohol is a pervasive part of our society, and its consumption can have widespread consequences. Plausible theoretical arguments can link alcohol to numerous adverse outcomes, such as death, crime, sexual activity, poor educational performance, unemployment, low job productivity, the use of related vices such as drugs and tobacco, poor inter- and intra-personal relationships, and mental and physical health problems. Importantly, the impacts of alcohol consumption are likely to vary across individuals. For example, cognitive ability or mental health may aid or hinder individuals in mitigating the effects of alcohol on judgement and choices.

Despite clear theoretical pathways, it is difficult to estimate causal relationships empirically because of either unobserved joint factors that determine both drinking and adverse outcomes (e.g., lack of self-control may precipitate both alcohol consumption and poor education outcomes) or reverse causality (e.g., poor mental health can induce one to consume alcohol). The most credible empirical estimates to date of the impacts of alcohol consumption come from regression discontinuity (RD) designs around the U.S. Minimum Legal Drinking Age (MLDA) of 21 years. The RD approach compares individuals just before and after their 21st birthday, and relies on the assumption that there are no other factors influencing alcohol consumption or outcomes of interest at this threshold. RD estimates of the MLDA have shown that legal access to alcohol increases mortality (Carpenter and Dobkin, 2009), lowers academic performance (Carrell, Hoekstra and West, 2011; Lindo, Swensen and Waddell, 2013), increases crime (Carpenter and Dobkin, 2015), and increases the use of marijuana and tobacco (Dee, 1999; Crost and Guerrero, 2012), amongst others.

In this paper, we expand the literature in two ways, using several novel datasets on U.S. Army soldiers. First, we examine outcomes that have not yet been studied in the context of the MLDA, including suicidal tendencies, psychological health, physical fitness, job-related infractions, and fitness for combat deployment. Second, we explore heterogeneity in the impacts of alcohol in terms of potential risk factors, including self-control, depression, coping ability, cognitive ability, and a family history of mental health problems or substance abuse.

Our population is all enlisted U.S. Army soldiers between 2009 and 2015. ${ }^{1}$ This is the only population we are aware of that contains such a rich panel of data on alcohol consumption and mental, behavioral, and physical outcomes. Outcomes from soldiers are important in their own right: there are 1.3 million active duty military members who are tasked with safeguarding our country, and the U.S. military is heavily involved in alcohol abuse prevention (Leskin, 2015). Heavy drink-

\footnotetext{
${ }^{1}$ Data is available for officers; however, only a handful of officers turn 21 years old while on active duty, as a four-year college degree is required to obtain an officer's commission.
} 
ing among service members has also been increasing since 2001 when the US entered its longest armed conflict to-date (Bray and Hourani, 2007; Oster et al., 2012). The rising trend in drinking and alcohol related problems is especially noticeable among those returning from deployment (Jacobson et al., 2008; Shen, Arkes and Williams, 2012; Bray, Brown and Williams, 2013), as many resort to alcohol as a way to cope with combat trauma.

Our data are drawn from multiple administrative databases. The Periodic Health Assessment (PHA) is a required, annual clinical health assessment which contains self-reports of alcohol and tobacco use, depressive symptoms, and suicidal thoughts, as well as the information that determines fitness for military deployment, a measure of job performance; the Global Assessment Tool (GAT) is an annual, self-administered and self-diagnostic psychometric assessment, identifies aspects of soldier's underlying psychological traits; annual physical fitness tests include scores for the number of push-ups and sit-ups completed at one time and the time taken to run two miles; and judicial and non-judicial punishments are recorded for any breach of military conduct or law.

Our first finding is that poor psychological health is correlated with alcohol consumption, both below and above 21 years of age. Second, there is a large discontinuous increase in alcohol consumption at age 21 , both in the likelihood of drinking (a 75\% increase) and the amount of drinking in any one sitting (increasing from about a third of a drink to an average of 2 drinks per day). In addition, those soldiers who were depressed at the baseline or have family history of mental health problems have larger change in their drinking behavior relative to all other soldiers. On the other hand, soldiers with better coping ability and those in the top quartile of AFQT distribution also have larger responses in drinking behavior when they turn 21. Finally, despite the increase in alcohol consumption, we do not observe any meaningful impacts on any of the short-term outcomes we observe, including suicidal tendencies, depression, tobacco use, physical fitness, psychological health, deployability, and job-related infractions. This null finding is precisely estimated, and is true over the entire population and when we stratify by soldiers' baseline psychological traits.

In sum, our findings suggest that while gaining legal access to alcohol increases overall drinking behavior among U.S. soldiers, it did not have immediate harmful consequences on the observable dimensions of soldier health, fitness, and job performance. However, this conclusion must be qualified by the limitations of our data and empirical setting. First, as with any RD around the MLDA, we are only able to look at the subset of individuals around their 21 st birthday. While alcohol consumption has been shown in laboratory settings to compromise physical and motor skills (Vogel-Sprott, 1979; Fogarty and Vogel-Sprott, 2002), our study population are young soldiers at or near their physical prime. It is thus unclear whether our results are externally valid to subjects 
who are younger or older than this sample. Second, the RD research design precludes us from looking at the long-term impact of alcohol consumption and from examining outcomes that may take time to manifest. Finally, despite our wealth of data, there are other important short-term outcomes that we do not observe, such as death, hospitalizations, and accidents. Nonetheless, our study adds important outcomes to a growing body of work of credible estimates of the effects of alcohol consumption, and demonstrates the importance of recognizing the variation in risk factors for alcohol consumption across the population.

The rest of the paper proceeds as follows. The next section describes our data and the setting of our sample. Section 3 discusses our empirical methods in detail, while Section 4 presents the main results. Finally, Section 5 concludes.

\section{Data and Sample}

\subsection{Data}

Our population is U.S. Army enlisted soldiers, and our data come from personnel records and routine health assessments that are collected on all enlisted soldiers. The Master Personnel File identifies the set of soldiers of an age close to their 21 st birthday and contains their demographic information such as birthdate, gender, race/ethnicity, the Armed Forces Qualifying Test (AFQT) score, and educational attainment. We merge the Master Personnel File to several other person-level databases which contain additional information on mental, physical, and behavioral outcomes.

Periodic Health Assessment. The Periodic Health Assessment (PHA) is a required annual assessment that is used primarily to screen for health problems and determine if a solider is fit for a combat deployment. Some of the data in the PHA is measured by a clinician, and some is selfreported by the service member. The clinically measured data include height, weight, vision and hearing ability, blood pressure, and cholesterol level. The self-reported data come from questions about current and past health symptoms and diseases, alcohol and tobacco use, behavioral and mental health history, and family history of mental health problems and chemical dependency.

Soldiers are informed that the elements of the PHA will not be shared with their superiors, and only used to assess their fitness for deployment. Nonetheless, it is possible that soldiers are not truthful with the self-reported PHA data, as they know that the PHA is used to determine eligibility for deployment, and deployability is a major determinant of promotion and career advancement. Soldiers wishing to appear mentally healthy may shade mental health issues or alcohol use, while soldiers wishing to not be deployed may fabricate these conditions. 
Global Assessment Tool The Global Assessment Tool (GAT) is a self-evaluation tool that was developed by the Army in 2009 as part of its efforts to improve soldiers' psychological resiliency. All soldiers are required to take the assessment yearly through an online module. They are told explicitly that their responses are confidential and will not be seen by their superiors. In contrast to the PHA, there is less reason to believe that soldiers would not be truthful on the GAT as there is not a direct link between responses and one's career.

The GAT contains 105 questions, either binary responses or on five- or 10-point scales, that are intended to assess a soldier's psychological health in 14 categories: depression, catastrophizing, positive affect, adaptability, coping ability, optimism, character, engagement in the workplace, friendship, loneliness, organizational trust, family satisfaction, family support, and spirituality. For full details of the GAT questionnaire see Lester et al. (2011).

Other Administrative Databases Physical fitness data come from the Digital Training Management System (DTMS), and include scores from the required annual assessments of three events: push-ups, sit-ups, and a 2-mile run. Lastly, we obtain records of all infractions recorded in a soldier's official file from the interactive Electronic Records of Management System (iPERMS). This data contains both judicial proceedings (i.e., court martial) as well as minor breaches of military conduct.

\subsection{Outcomes}

Next we describe the outcome measures that are drawn from these various databases. We examine the impacts of legal access to alcohol on both soldiers' drinking behavior and outcomes that are known to be correlated with alcohol consumption or could potentially be influenced by alcohol consumption. Theoretical mechanisms through which alcohol could influence these outcomes include compromised judgment and impaired physical and/or motor skills.

Alcohol consumption. We define four measures of alcohol consumption from questions on the PHA. The first question is: How often do you have a drink containing alcohol?, to which the soldier can respond: "never", "monthly or less", "2-4 times a month", "2-3 times a week", or "4 or more times a week." From this, we define an indicator for whether a person drinks alcohol. Given the vagueness of the text, it is unclear whether this question is asking about whether a person has ever drank alcohol, or whether they have drank alcohol recently. It is worth noting that among our under-21 sample, close to $13 \%$ of the soldiers had consumed alcohol. We also calculate from this question the proportion of days in which a person drinks, constructing the measure logically from responses. For example, those who reported drinking "monthly or less" are assigned a value of $1 / 30$, those who report "2-4 times a month" are assigned 3/30, and so forth. 
If the answer to the first question is anything other than "never", the respondent proceeds to answer about the intensity of their drinking behavior. They were next asked How many drinks containing alcohol do you have on a typical day when you are drinking? (1-2, 3-4, 5-6, 7-9, or $10+)$, from which we define a linear variable of the number of drinks on a typical drinking day, imputing the midpoint of the category ranges and coding "10+" as 10 drinks. Finally, respondents were asked: How often do you have six or more drinks on one occasion? (never, less than monthly, monthly, weekly, or daily), from which we define the proportion of "binge" drinking days in a similar manner to the proportion of drinking days.

Tobacco use. Past studies have documented that alcohol use and tobacco use have common risk factors (Verdejo-García, Lawrence and Clark, 2008). Using responses from the PHA, we define three measures of smoking on both the extensive and intensive margins. On the extensive margin, soldiers were asked Do you use any kind of tobacco products?; close to 30\% of those under 21 years old reported they do. On the intensive margin, smokers were first asked about the number of cigarettes smoked, and we define a moderate or heavy smoker as 11 or more cigarettes per day (results are robust to the use of the continuous number of cigarettes smoked). They were then asked three questions about their level of nicotine dependency that, along with the number of cigarettes smoked per day, facilitates the calculation of the Fagerstrom score (Heatherton et al., 1991): How soon after waking up do you smoke your first cigarettes; Do you find it difficult to refrain from smoking in places where it is forbidden; Do you smoke more frequently in the morning; and Do you smoke even if you are sick in bed most of the day. The Fagerstrom score ranges from 0 to 10, and we classify those with a score of 5 or higher as having a moderate or high nicotine dependence (results are robust to the use of the linear Fagerstrom score). Amongst smokers under 21 years old, $26 \%$ are moderate or heavy smokers, and $14 \%$ are classified as having a moderate or high nicotine dependence.

Depression and suicide ideation. Alcohol use been shown to be correlated with both major depression and suicide ideation (Wang and Patten, 2001; Fergusson, Boden and Horwood, 2009; LeardMann et al., 2013; Fuehrlein et al., 2016; Thompson and Swartout, 2017). However, there is no evidence to date on the causal pathways at play. The PHA contains nine screening questions for depression which ask about mood and behavior in the last two weeks. Following the Army's psychological health referral guideline, we define a soldier to be at risk of clinical depression if he answered "more than half the days" or "nearly every day" to at least one of these nine questions. ${ }^{2}$

\footnotetext{
${ }^{2}$ The exact wording in the PHA is: Over the last two weeks, how often have you been bothered by any of the following problems? (1) Little interest or pleasure in doing things? (2) Feeling down, depressed or hopeless? (3) Trouble falling asleep or staying asleep, or sleeping too much, (4) Feeling tired or having little energy, (5) Poor
} 
In our sample, $6.5 \%$ of soldiers under 21 were screened positive for depression. The PHA also has one question concerning suicide ideation. We define the indicator self-harm thoughts if they answer anything other than "never" to the question How often in the last 2 weeks were you bothered by "thoughts that you would be better off dead, or of hurting yourself in some way." Self-harm thoughts are rare, with only $0.1 \%$ of soldiers in the under- 21 sample defined as such.

Fitness for deployment. A soldier is determined to be fit for deployment "to an austere environment" if he has a PULHES score above the occupation-specific minimum. The PULHES is a function of six factors: (P)hysical capacity or stamina; (U)pper extremities; (L)ower extremities; (H)earing and ears; (E)yes, and (P)sychiatric stability. Approximately 93\% of our under-21 sample were deemed to be fit for deployment.

Coping ability and self control. The GAT assesses two psychological traits, coping ability and self-control, that may be influenced by alcohol consumption through disruptions in the brain's neurotransmitter balance (Verdejo-García, Lawrence and Clark, 2008). We define self-control as the answer to a single question from the GAT measured on a scale of 0-10: Think about how you have acted in actual situations during the past four weeks. Select a number from 0 to 10 according to how often you showed/used self control. We define coping ability as the sum of responses from 8 questions as on the GAT, each with a score of 1 to 5: How well do the following statements describe you-(1) For things I cannot change, I accept them and move on; (2) I control my emotions by changing how I think about things; (3) When something stresses me out, I try to avoid it or not think about it; (4) When something stresses me out, I try to solve the problem; (5) When bad things happen, I try to see the positive sides; (6) I usually keep my emotions to myself; (7) When something stresses me out, I have effective ways to deal with it; and (8) When I am feeling upset, I keep my feelings to myself. We take the sum of responses from these 8 questions to form the coping ability outcome, where a higher score reflects a better coping ability.

Physical fitness. Laboratory settings have shown alcohol consumption can result in slower movement and poorer coordination. Our next set of outcomes thus capture a soldiers' physical fitness. The PFT is a twice-yearly assessment of soldier's muscular strength and physical endurance consisting of three events: push-ups, sit-ups, and a 2-mile run. Each event is scored between 0 and 100 , and a 60 is required in all events to pass. Passing scores are assigned by gender and age group for the number of push-ups and pull-ups completed, and the time required for the 2-mile run. For

appetite or overeating, (6) Feeling bad about yourself - or that you are a failure or that you have let yourself or your family down, (7) Trouble concentrating on things, such as reading the newspaper or watching television, (8) Moving or speaking so slowly that other people could have noticed. Or the opposite - being so fidgety or restless that you have been moving around a lot more than normal, (9) Thoughts that you would be better off dead, or of hurting yourself in some way. 
example, for a 21-year old male, the passing ranges are: 42-71 push-ups, 53-78 sit-ups, a 2-mile run time between 15 minutes 54 seconds and 13 minutes. (For full details of the test, see Army (2012).) We consider as outcomes the separate event scores as well as the aggregate score (sum across all three events).

Job-related infractions. Our final set of outcomes identify all recorded breaches of military conduct or regulation. There is evidence from non-military populations that crime increases with legal access to alcohol (Carpenter and Dobkin, 2011), with the plausible pathway being alcohol impairing judgement. The job of a soldier is unique in that one is always subject to the the Uniform Code of Military Justice (UCMJ) regardless of whether the soldier is on duty; thus, any breach of the UCMJ can be considered a job-related infraction.

The iPERMS database contains various levels of offenses varying in severity. We classify these offense records into three categories, and consider offenses of each type separately, as well as an aggregate measure of having committed any offense. A level 1 offense is a minor offense known as a "letter of reprimand." It is recorded by the soldier's commanding officer for a broad range of behaviors deemed unbecoming of a military service member, such as insubordination, an initial report of sexual harassment, or disorderly conduct. These types of offenses do not result in punishments, but the letter stays on the soldier's personnel record and may affect future promotions or assignments. A level 2 offense is when a soldier goes through proceedings under Article-15 of the UCMJ. When a soldier commits an offense covered by the UCMJ, his commanding officer can decide to process him under Article-15 or bring formal charges. Article-15 proceedings can result in punishments (such as demotion, confinement, jail time for no more than 30 days, extra duties), but do not result in a criminal record. Soldiers who undergo Article-15 proceedings do not go through a formal adjudication process (although soldiers have the right to request a full military legal trial). Finally, a level 3 offense is one which the commanding officer deems serious enough to merit a full judicial hearing, known as military court martial. If convicted under a court martial, the soldier will have a criminal record and receive punishments that range from demotion, fines, jail time or dishonorable discharge (which affect his post-military benefits). One thing to keep in mind is that while we can classify types of offenses, our data does not indicate the nature of any offense. Offenses are relatively rare, with only $3.4 \%$ of the under- 21 sample having at least one offense.

\subsection{Sample Selection}

Using a window of 6 months above and below the 21st birthday, we first identify all soldiers in the Master Personnel File who were aged 20.5 to 21.5 at anytime between 2009 and 2015. 
We exclude soldiers stationed either outside the U.S. and or on bases within 50 miles of the U.S. borders with Mexico and Canada, as commanders at these locations have the discretion to adopt an MLDA other than 21 years old. We also exclude any soldiers who do not have a GAT test before their 21st birthday. Our working sample size is 29,329 soldiers, but some outcomes are not observed for every soldier in the window around their 21 st birthday. For instance, in the PHA sample which we use for our main analysis, we only have 11,905 observations. In contrast we are able to capture more soldiers in the PFT sample $(n=28,998)$ since soldiers are required to take the test two times a year.

Table 1 summarizes the characteristics of the individuals in our analysis: the majority are male $(83 \%)$ and white $(59.9 \%)$, virtually all have a High School diploma (a requirement for military service), and the average AFQT score is the 56th percentile. We summarize the outcome variables as we discuss our results below.

\section{Methods}

We use a Regression Discontinuity (RD) design which exploits the discontinuity in legal access to alcohol at age 21. Outcomes for individuals observed just prior to their 21 st birthday serve as the counterfactual for individuals observe just after their 21st birthday. Causal identification of the impact of legal access to alcohol rests on the assumption that no other factors related to outcomes of interest changed at this threshold other than alcohol access becoming legal, and also that there is no systematic sorting of when the PHA, PFT, and GAT were taken. ${ }^{3}$

Formally, for each person $i$, let $D_{i}=a g e_{i}-21$ be the distance in days between the observation of the outcome and the person's 21 st birthday, and $T_{i}$ be an indicator of being over 21: $T_{i}=1\left\{D_{i} \geq\right.$ $0\} . Y_{i}$ are outcomes of interest, such as measures of alcohol consumption and health measures, and we estimate models of the following form:

$$
Y_{i}=\beta_{0}+\beta_{1} T_{i}+g\left(D_{i}\right)+\gamma X_{i}+\varepsilon_{i}
$$

where $D=\left(D, D^{2}\right)^{\prime}$ and $g\left(D_{i}\right)=\alpha_{0} D+\alpha_{1} T * D$. Thus, $g(D)$ is a 2 nd order polynomial of $D$ in our parametric specification, with interactions of the over 21 indicator with the quadratic function. $\beta_{1}$ is the discrete change in $Y_{i}$ at the discontinuity. For variance reduction purposes, we also include $X$, a set of control variables in some of our specifications. Standard errors are adjusted to allow for

\footnotetext{
${ }^{3}$ While a subset of soldiers could have been drinking before turning age 21 , and this early drinking behavior could have affected their GAT score, we are exploiting variation from increased alcohol access at age 21. As such, the interpretation of the treatment effect is conditional on their GAT score prior to age 21 and is the effect of the marginal increase of access to alcohol at age 21 .
} 
an arbitrary correlation in errors at the level of $D$, the distance to age 21 , to account for potential misspecification as suggested by Lee and Card (2008).

While in principle we could use nonparametric local linear regression or other techniques, the underlying data (in particular, of age) are not actually continuous but rather discrete. Following Lee and Card (2008), we then assess the adequacy of our parametric representation by comparing our model with a non-parametric specification that includes a full set of indicators for each value of $D$ (that is, for each day away from the 21 st birthday):

$$
Y_{i}=\sum_{d} \alpha_{d} Z_{d i}+\gamma X_{i}+\mu_{i}
$$

where $Z_{d}$ is a dummy variable that equals 1 if the soldier $i$ 's age is equal to $d$, and 0 otherwise. The coefficients $\alpha_{d}$ are represented as open circles in the figures we discuss below, while the quadratic polynomial fit of the above equation are represented as connected lines/curves. These plots allow for a simple "eyeball" test of the extent to which our parametric formulation is a reasonable representation of the data.

To confirm our visual examination with a more formal test, we calculate a goodness of fit statistic as developed in Lee and Card (2008) and as summarized in Lee and Lemieux (2010),

$$
G=\frac{\left(E S S_{r}-E S S_{u r}\right) /(J-K)}{E S S_{U R} /(N-J)},
$$

where $E S S_{r}$ is the estimated sum of squares of the restricted (quadratic) model while $E S S_{u r}$ is the estimated sum of squares of the unrestricted (fully-saturated) model. $G$ follows a $F(J-K, N-J)$ distribution where $J$ is the number of values taken by $D$ and $K$ is the number of parameters in the restricted model. With this $F$ - statistic we can test the null hypothesis that the polynomial fit is as good or has as much explanatory power as the fully flexible model. In our models, the $F$ - statistics indicate that the restricted and unrestricted models have similar goodness of fits.

\subsection{Heterogeneity Analysis}

A novel contribution of our analysis is that we are able to estimate the heterogeneous impacts of the MLDA in terms of risk factors for alcohol consumption. We explore the following five dimensions of heterogeneity, using soldier's score on that dimension before they turned 21 years old.

Depression, Self-control, and Coping Ability. In our main analysis, we consider depression, self-control, and coping ability as outcomes that may be be affected by alcohol use; however, the direction of causality could run the other way, whereby these psychological attributes are the risk 
factors leading to drinking (Verdejo-García, Lawrence and Clark, 2008).

Self-control and coping ability are already described in section 2.2 and come from the GAT. For depression, we use screening questions from the PHA as our outcome, but we stratify soldiers based on their GAT depression scale for the heterogeneity analysis. While there is overlap in the questions, the PHA follows clinical screening questions more closely and contains more details. In contrast, the GAT depression scale is based on fewer questions and is intended to capture a soldier's inherent tendencies toward being depressed. Specifically, GAT measures depression using 5 questions. Respondents were asked to rate on a 5-point scale (from "not at all" to "every day") how often in the past four weeks they were bothered by any of the problems listed. Examples of the problems include "Feeling down, depressed or hopeless," and "Feeling very angry." ${ }^{4}$ We take the sum of scales across all responses to form the baseline depression scale.

Armed Forces Qualifying Test percentile. The AFQT percentile is computed based on test scores from the following aptitude tests: arithmetic reasoning, mathematics knowledge, paragraph comprehension, and word knowledge. The Army uses results from these tests to assign soldiers to suitable military occupation. It is normalized so the AFQT scores are reported as percentiles between 1 and 99. The U.S. Army requires a minimum score of 31 on the AFQT for a person to be enlisted. A score below 31 would require a waiver. As Table 1 shows, the average AFQT score in our sample is 56 .

Family history of mental health problems and/or chemical dependency. On the PHA, a soldier was asked to identify whether their parents, grandparent, and/or siblings had mental health problems or chemical dependencies. ${ }^{5}$ We classify soldiers into those with and without any family history of mental health or chemical dependency, and approximately $13 \%$ of our sample reported having any family history. Our results are robust to looking separately at histories of mental health problems and chemical dependencies, as well as using the number of family members with a reported condition.

\footnotetext{
${ }^{4}$ The complete questions in the GAT are: (1) Feeling down, depressed or hopeless, (2) Feeling tired or having little energy, (3) Poor appetite or overeating, (4) Feeling very angry, (5) Trouble concentrating on things, such as reading the newspaper or watching television.

${ }^{5}$ Mental health problems include any of the following disorders: Generalized anxiety disorder, Depression, Bipolar disease, Schizophrenia, Obsessive compulsive disorder, Attention deficit disorder, Split personality disorder, Personality disorder, Adjustment disorder, Eating disorder, Tourette syndrome, Agoraphobia, Autism, Seasonal affective disorder, Suicide, Multiple disorders. Chemical dependency includes any of the following categories: alcohol, cocaine/crack, heroin, marijuana, methamphetamine, narcotics, glue/solvents, LSD, benzodiazepines, Ecstasy, multiple dependency, other chemical dependency.
} 


\section{Results}

\subsection{The impact of MLDA on alcohol consumption}

We first examine the impact of legal access to alcohol on self-reported alcohol consumption. Figure 2 presents four different measures of alcohol consumption amongst soldiers in the 180 days before and after their 21st birthday. A visual comparison of the parametric estimates and the daily means suggest that the quadratic parameterization fits the data reasonably well. We confirm this with the $F$-statistic described above, which tests the null hypothesis that the polynomial model has as much explanatory power as the fully flexible (non-parametric) model.

The top left panel of Figure 2 shows that approximately $13 \%$ of soldiers report having drank any alcohol prior to their $21 \mathrm{st}$ birthday. The bottom left panel shows that soldiers consume very little prior to turning age 21, on average about a third of a drink (this measure includes those who do not drink as drinking 0 drinks). The top right and bottom right panels of Figure 2 show that amongst those who drink at all, the proportion of drinking days is very low and the proportion of binge drinking days (having six or more drinks on one occasion) is even lower.

For the first two months after the 21 st birthday, there is a clear rising propensity in the intensive and extensive margins of alcohol consumption, which then plateau at new higher levels. About $70 \%$ of soldiers report having ever drank alcohol by the 2 nd month after their 21 st birthday, and the number of drinks on a typical drinking day rises to about 2. The proportion of drinking days rises to about $10 \%$, and while the proportion of binge drinking days also rises it is still low, at about $0.02 \%$. This ramp-up after the 21 st birthday is consistent with the fact that soldiers must wait until they are off-duty before they can purchase alcohol and drink - depending on one's occupation or phase of training, this freedom to drink may be delayed by weeks or months.

Table 2 confirms the visual impacts seen in Figure 2, although the point estimates are muted as our regression model does not distinguish between the post-birthday ramp-up in drinking and the eventual plateau. For example, the RD point estimate for drinking at all is 9.5 percentage points, which is an increase of $74.8 \%(=0.095 / 0.127)$ even though 2 months after the 21 st birthday the increase over the pre-21 rate is over 5-fold ( $13 \%$ to $\sim 70 \%$ ).

It is worth noting that these estimates of the impact of the MLDA on alcohol consumption are slightly larger than those found amongst both the U.S. population as a whole (a 6 percentage point increase found in Carpenter and Dobkin (2009) using the National Health Interview Survey) and the U.S. college student population (a 6.5 percentage point increase found in Lindo, Swensen and Waddell (2013) using the NLSY 97). The pre-21 alcohol consumption we observe amongst 
soldiers is also lower than has been reported in the civilian population. These low rates could be reflecting under-age soldiers' unwillingness to report alcohol use: soldiers may not know, or not believe, that the PHA is not shared with their direct superiors. However, young soldiers generally live on bases with limited access to alcohol and face strict penalties for drinking under the legal age, supporting the validity of these low rates. That alcohol consumption slopes upward in the next 60 days after turning 21, as opposed to a discontinuous change at exactly 21 , suggests that access to alcohol is driving this change in alcohol behavior, further validating our research design.

\subsection{The impact of MLDA on mental health, physical fitness, and job performance}

Figure 3 presents visual evidence of the change in selected outcomes around the 21st birthday. As with the alcohol consumption measures, the quadratic parametric specifications fit the data reasonably well (this is also confirmed by the $F$ - statistics described above). Table 2 contains RD estimates of all of our outcomes of interest.

By and large, we observe no systematic differences in any of the outcomes we study for soldiers before and after the 21 st birthday. That is, virtually all of these RD estimates are small in magnitude, precisely estimated (standard errors are small, partially stemming from the large sample sizes), and statistically indistinguishable from zero. ${ }^{6}$ For instance, in the PHA sample, $29.7 \%$ of the soldiers reported being a smoker just before they turned 21. The estimated impact of turning age 21 is to increase the prevalence of smoking by 2.2 percentage points, but this estimate is not statistically distinguishable from 0 . Our finding on smoking is consistent with Yörük and Yörük (2011) who show that the MLDA has a small and insignificant impact on cigarette (and marijuana) use. $^{7}$

That our estimates of the impacts of MLDA are indistinguishable from zero are also not being driven by the baseline mean. For instance, $93.3 \%$ of soldiers are classified as "Fit for deployment" prior to turning 21. The RD estimate of turning 21 is to lower this percentage by 0.8 percentage points, but then again the estimate is not statistically different from zero. We do find that the impact of the MLDA on job-related infractions ("Any offense") is significant at the 5 percent level (and is driven by level 1 offenses), but is extremely small in magnitude and economically insignificant. This is in part due to the low-frequency nature of this event, which is why we present the RD in Figure 3 aggregated to the weekly level. In addition, Appendix Table 4 shows that

\footnotetext{
${ }^{6}$ With the large number of outcomes we consider, one may be concerned about issues of multiple inference; however, common adjustments will tend to increase $\mathrm{p}$-values of hypothesis tests, further supporting our general finding of no impacts of the MLDA on these outcomes (Savin, 1980).

${ }^{7}$ The military has a "Zero Tolerance" policy on the use of illicit drugs, the consequence for which is expulsion from service (Bachman et al., 1999); it is therefore not surprising that the PHA does not ask about marijuana or other illicit drug use.
} 
the significant estimate is purely an artifact of the functional form rather than a true decline in job-related infractions post-21.

\subsection{Heterogeneity of the alcohol access effect by risk factors}

The null results we described in the previous section might mask potential negative impacts of alcohol access experienced by certain segments of the population. Next, we analyze the extent to which soldiers' baseline psychological and cognitive profiles, as measured by the five traits described in section 3.1, might act as mediating factors in the impact of alcohol consumption on behavioral outcomes.

In practice, we split our sample into the top quartile, interquartile range, and the bottom quartile for coping ability, depression, self control, and AFQT score, and into those with and without a family history of substance use/mental health problems. We then estimate the RD model separately for each group. In addition, the sample size does not distribute exactly as $25 \%, 50 \%$, and $25 \%$ across the three quartile ranges, due to the discrete nature of the scores. However, all results are robust to other parameterizations of these variables.

Figures 4-8 show that there is substantial differences in the pre-21 means of drinking and the other outcomes by the five dimensions of heterogeneity we study. For example, Figure 4 shows that over $15 \%$ of those whose self-control score is in the bottom quartile drinks alcohol before they turn 21 , compared to only $10 \%$ from the top quartile. Those in the bottom quartile are also more likely to screen positive for depression ( $11 \%$ in the bottom quartile versus $5 \%$ in the top quartile), to have thoughts of self harm ( $0.9 \%$ versus $0.4 \%)$ and to commit offenses ( 2 per 10,000 soldiers on a given day in the bottom quartile versus 1.3 in the top quartile). We observe similar patterns when we examine pre-21 means of the outcomes by the distribution of coping ability (Figure 5) and of baseline depression (Figure 6).

Differences in pre-21 outcomes are particularly noticeable between soldiers with and without a family history of mental health problems or chemical dependencies. In particular, Figure 8 shows that, before soldiers turned 21, those with a family history are more than 3 times more likely to be screened positive for depression (5\% among those without family history versus $18 \%$ among those with family history of mental health problems of chemical dependency), more than 3 times more likely to have suicidal thoughts $(0.5 \%$ versus $1.7 \%)$ and to commit an offense $(0.6$ per 10,000 soldier days versus 2).

Along the AFQT dimension (Figure 7), those who are in the top quartile of the AFQT distribution are more likely to be drinking alcohol before turning 21 than those in the bottom quartile (11\% among bottom quartile versus $14 \%$ among top quartile). But those in the bottom quartile of AFQT 
distribution are a bit more likely to have suicidal thoughts (1.1\% versus $0.8 \%)$ or commit offense (1.6 per 10,000 soldier on a given day versus 1.1). One thing to note is that across all 5 traits, we generally do not see differences in physical outcomes (total fitness score and fit for deployment) by the distribution of the trait.

These patterns are generally consistent with the descriptive findings in Marsden (2014), which uses data from select years between 1980 to 2008 of the Department of Defense Surveys of Health Related Behaviors Among Active Duty Military Personnel. For instance, in a multivariate logit adjusting for demographics and other factors, they find that prevalence of suicide ideation is significantly related to depression symptoms and avoidance coping. Marsden (2014) also find heavy drinking is not significantly related to active coping.

Table 3 report estimates of the causal impact of legal access to alcohol on selected outcomes (the remaining outcomes are reported in Appendix Table 5 for efficiency). Each column represents a separate RD model for that sub-sample of soldiers. For example, when we categorize soldiers by their baseline depression score, the RD estimates show that those who score in the bottom quartile of depression have larger response to MLDA (probability of drinking goes up by 0.13 , $\mathrm{p}<0.01$ ) than those in the top quartile (probability of drinking goes up by $0.05, \mathrm{p}>0.10$ ). We also observe larger responses among those with family history of mental health or chemical dependency problems ( $R D$ estimates are 0.08 versus 0.17 , both $\mathrm{p}<0.05$ ). Interestingly, those with better coping ability have larger responses to MLDA than those in the bottom quartile of coping $(0.12, \mathrm{p}<0.05$ versus 0.076, $\mathrm{p}>0.1$ ); and those in the top quartile of AFQT distribution also have larger response to MLDA than those in the bottom quartile ( 0.148 versus $0.088, \mathrm{p}<0.05$ for both).

The stratified analysis on drinking outcomes suggest that MLDA mainly affects those with better cognitive ability (better AFQT and coping skills)-soldiers who are likely to be workers with better productivity to start with and are better equipped to cope with the stressful military environment. As a result, we might not expect to see significant loss in worker job performance when these soldiers gain legal access to alcohol.

Indeed, when we examine the non-drinking outcomes, we find no significant negative or positive impacts of turning 21. However, part of the null finding might be due to the low frequency of the outcomes. For example, the RD estimates for suicidal thoughts is 0.003 (i.e., 0.3 percentage point increase off a base rate of $0.6 \%$ ) for those without family history and 0.024 (i.e., 2.4 percentage point increase off a base rate of $2.3 \%$ ) for those with family history of mental health problems or chemical dependency. Even though the magnitude of the estimate is fairly large in the practical sense, the standard errors are also very large due to the fact that very few soldiers reported having 
suicidal thoughts.

\subsection{Validity of the $\mathrm{RD}$ and robustness of main results}

One critical assumption for the RD to work in this context is that soldiers are not systematically manipulating (sorting into) when they take the PHA, PFT, and GAT to either before or after their 21st birthday; and that alcohol consumption is indeed impacted upon gaining legal access after one's 21 st birthday.

For all practical purpose, there is no reason to believe that soldiers would purposefully choose to take either assessment before or after turning 21, since soldiers do not reap any benefit whether the assessments were taken before or after their birthday. Empirically, Figure 1 shows the distribution of ages across all our samples when the tests were taken, and there does not appear to be bunching before or after the 21 st birthday. These figures suggest soldiers are not manipulating when they take the PHA, GAT, and fitness test around their 21st birthday, thus verifying the first assumption for RD validity. The results discussed in Section 4.1 clearly demonstrates that the second assumption holds as well.

To check whether our null findings are statistical artifacts of our modeling choices, Appendix Tables 2, 3, and 4 report estimates of the impact of turning 21 on the PHA, PFT, GAT, and iPERMS outcomes, respectively, across six different models: linear, quadratic, and cubic specifications of $g(D)$ with and without controls of $X$ as discussed in the Methods section above. These tables also report the $F$-statistic and the mean values of the outcomes. These tables verify (1) that the quadratic model is a good representation of our data and (2) that the results are robust to the inclusion or exclusion of the controls.

In addition to verifying the robustness of our results to the inclusion of soldiers' characteristics, we can also test whether these characteristics themselves vary across the age 21 threshold. Specifically, soldiers just under and over 21 should have baseline characteristics that are the same on average. Figures 1 showed that soldiers are not selectively sorting when they take mental and physical health and fitness assessments relative to their 21 st birthday. This time we would like to verify whether $E(X \mid D)$ is continuous through their 21 st birthday, at $D=0$. For instance, one may worry that high cognitive ability soldiers disproportionately take the assessments after their $21 \mathrm{st}$ birthday. To the extent that soldiers' cognitive ability independently affect outcomes, this factor could in principle confound our estimates of the treatment effect of legal access to alcohol.

Appendix Table 1 reports our results testing for smoothness in the observable characteristics of soldiers across age 21 . Across the 32 regressions we estimate (eight outcomes for each of the 4 databases), the discontinuity is not statistically distinguishable from zero at the $5 \%$ level in all cases 
except for one. Note that similar to our analyses of multiple outcomes above, these critical values are unadjusted for the problem of multiple comparisons, which can lead one to more rejections of the null hypothesis when the null is in fact correct (Savin 1980).

In the case that is significant at the 5\% level, we find higher share of women taking the PHA at just over age 21 by 5.47 percentage points (but the gender imbalance is not found in the other 3 samples). To the extent that these discontinuities are real, an increase in the share of women at 21 would lead us to understate the effects of MLDA on alcohol consumption at 21, since women on average drink less than men. Given that we do not find significant negative effects of MLDA on other behavioral outcomes, we are not concerned about the gender imbalance across age 21 .

\section{Conclusion}

In this paper, we estimate the impact of legal access to alcohol on a wide range of behavioral and physical outcomes of young U.S. Army soldiers, and we explore whether these impacts vary with risk factors for alcohol abuse.

Using data on all soldiers between 2009 and 2015, we observe a large and significant increase in drinking after the 21st birthday overall, and the increases are largest amongst those who were depressed, had a family history of mental health problems, had better coping ability, and had higher cognitive ability. Despite the large increase in consumption, we do not find any meaningful impacts of legal access to alcohol - overall or in any sub-group - on any of the short-term outcomes we observe, including suicidal tendencies, depression, tobacco use, physical fitness, psychological health, deployability, smoking, and job-related infractions.

How do our results add to the current knowledge of drinking behaviors in the military? Drinking and use of tobacco products have long been part of the military culture (Oster et al., 2012). Alcohol is even used by unit leaders as a way to build unit cohesion and reward the completion of difficult tasks. As one USMC sergeant recounted in a New York Times Op-Ed of his experience, beer consumption and underage drinking are common within the barracks even though alcohol is prohibited inside the military compound (Brennan, 2012). Soldiers do know they will get punished if they get caught drinking underage or drinking hard alcohol within the barracks. Thus, it makes sense that using data from the military workplace, we find increases in alcohol have no meaningful impact on soldiers' physical and mental health and adverse behaviors, even as attaining legal access increased their consumption.

While the null findings on this set of short-term outcomes are encouraging from a public health viewpoint, and perhaps suggest that soldiers are drinking responsibly, more information is needed 
to understand the full impact of alcohol consumption amongst service members; thus, our results need to be interpreted carefully if they are to be used to inform public policy. For one, it must be recognized that there could be medium- and long-run consequences of drinking that manifest over time and that we can not observe through this RD design on the MLDA. And, we do not observe important short-term outcomes such as injury or death, which have been shown to increase with legal access (Carpenter and Dobkin, 2009). Finally, while young soldiers are broadly representative of the high-school educated population, the restricted and controlled environment of the military invalidate the extrapolation of our results to the civilian population of 21 year olds. 


\section{References}

Army, US. 2012. "FM 7-22 Army Physical Readiness Training." Washington, DC: Headquarters, Department of the Army.

Bachman, Jerald G, Peter Freedman-Doan, Patrick M O'malley, Lloyd D Johnston, and David R Segal. 1999. "Changing patterns of drug use among US military recruits before and after enlistment." American Journal of Public Health, 89(5): 672-677.

Bray, Robert M., and Laurel L. Hourani. 2007. "Substance use trends among active duty military personnel: findings from the United States Department of Defense Health Related Behavior Surveys, 1980-2005." Addiction, 102(7): 1092-1101.

Bray, Robert M., Janice M. Brown, and Jason Williams. 2013. "Trends in Binge and Heavy Drinking, Alcohol-Related Problems, and Combat Exposure in the U.S. Military." Substance Use \& Misuse, 48(10): 799-810.

Brennan, Thomas James. 2012. "In the Military, the Drinking Can Start on Day 1." New York Times.

Carpenter, Christopher, and Carlos Dobkin. 2009. "The effect of alcohol consumption on mortality: regression discontinuity evidence from the minimum drinking age." American Economic Journal: Applied Economics, 1(1): 164-182.

Carpenter, Christopher, and Carlos Dobkin. 2011. "The minimum legal drinking age and public health." The Journal of Economic Perspectives, 25(2): 133-156.

Carpenter, Christopher, and Carlos Dobkin. 2015. "The minimum legal drinking age and crime." Review of Economics and Statistics, 97(2): 521-524.

Carrell, Scott E, Mark Hoekstra, and James E West. 2011. "Does drinking impair college performance? Evidence from a regression discontinuity approach." Journal of Public Economics, 95(1): 54-62.

Crost, Benjamin, and Santiago Guerrero. 2012. "The effect of alcohol availability on marijuana use: Evidence from the minimum legal drinking age." Journal of Health Economics, 31(1): 112121.

Dee, Thomas S. 1999. "The complementarity of teen smoking and drinking." Journal of Health Economics, 18(6): 769-793.

Fergusson, David M, Joseph M Boden, and L John Horwood. 2009. "Tests of causal links between alcohol abuse or dependence and major depression." Archives of General Psychiatry, 66(3): 260-266.

Fogarty, Jennifer N, and Muriel Vogel-Sprott. 2002. "Cognitive processes and motor skills differ in sensitivity to alcohol impairment." Journal of Studies on Alcohol, 63(4): 404-411. 
Fuehrlein, Brian S, Natalie Mota, Albert J Arias, Louis A Trevisan, Lorig K Kachadourian, John H Krystal, Steven M Southwick, and Robert H Pietrzak. 2016. "The burden of alcohol use disorders in US military veterans: results from the National Health and Resilience in Veterans Study." Addiction, 111(10): 1786-1794.

Heatherton, Todd F, Lynn T Kozlowski, Richard C Frecker, and Karl-Olov Fagerstrom. 1991. "The Fagerström test for nicotine dependence: a revision of the Fagerstrom Tolerance Questionnaire." British Journal of Addiction, 86(9): 1119-1127.

Jacobson, Isabel G, Margaret AK Ryan, Tomoko I Hooper, Tyler C Smith, Paul J Amoroso, Edward J Boyko, Gary D Gackstetter, Timothy S Wells, and Nicole S Bell. 2008. "Alcohol use and alcohol-related problems before and after military combat deployment." JAMA, 300(6): 663-675.

LeardMann, Cynthia A, Teresa M Powell, Tyler C Smith, Michael R Bell, Besa Smith, Edward J Boyko, Tomoko I Hooper, Gary D Gackstetter, Mark Ghamsary, and Charles W Hoge. 2013. "Risk factors associated with suicide in current and former US military personnel." JAMA, 310(5): 496-506.

Leskin, Gregory. 2015. "Preventing Substance Abuse in Military Members and Their Families." Prevention Tactics, 9(14).

Lester, Paul B, Peter D Harms, Denise J Bulling, Mitchel N Herian, and Seth M Spain. 2011. "Evaluation of Relationships Between Reported Resilience and Soldier Outcomes. Report\# 1: Negative Outcomes (Suicide, Drug Use, \& Violent Crimes).” DTIC Document.

Lindo, Jason M, Isaac D Swensen, and Glen R Waddell. 2013. "Alcohol and student performance: Estimating the effect of legal access." Journal of Health Economics, 32(1): 22-32.

Marsden, Robert M. Bray; Laurel L. Hourani; Jason Williams; Marian E. Lane; Mary Ellen. 2014. Understanding Military Workforce Productivity: Effects of Substance Abuse, Health, and Mental Health. Springer.

Oster, Maryjo, Emily Morden, Treatment Committee on Prevention, Diagnosis, Management of Substance Use Disorders in the U. S. Armed Forces, Board on the Health of Select Populations, and Institute of Medicine. 2012. Substance Use Disorders in the U.S. Armed Forces. Washington, D.C.:National Academies Press.

Savin, Neil E. 1980. "The Bonferroni and the Scheffe multiple comparison procedures." The Review of Economic Studies, 255-273.

Shen, Yu-Chu, Jeremy Arkes, and Thomas V Williams. 2012. "Effects of Iraq/Afghanistan deployments on major depression and substance use disorder: analysis of active duty personnel in the US military." American Journal of Public Health, 102(S1): S80-S87.

Thompson, Martie P, and Kevin Swartout. 2017. "Epidemiology of suicide attempts among youth transitioning to adulthood." Journal of Youth and Adolescence, 1-11. 
Verdejo-García, Antonio, Andrew J Lawrence, and Luke Clark. 2008. "Impulsivity as a vulnerability marker for substance-use disorders: review of findings from high-risk research, problem gamblers and genetic association studies." Neuroscience \& Biobehavioral Reviews, 32(4): 777-810.

Vogel-Sprott, MD. 1979. "Acute recovery and tolerance to low doses of alcohol: differences in cognitive and motor skill performance." Psychopharmacology, 61(3): 287-291.

Wang, JianLi, and Scott B Patten. 2001. "Alcohol consumption and major depression: findings from a follow-up study." The Canadian Journal of Psychiatry, 46(7): 632-638.

Yörük, Barış K, and Ceren Ertan Yörük. 2011. "The impact of minimum legal drinking age laws on alcohol consumption, smoking, and marijuana use: Evidence from a regression discontinuity design using exact date of birth." Journal of Health Economics, 30(4): 740-752. 
Figure 1: The distribution of the age of soldiers observed in our databases.
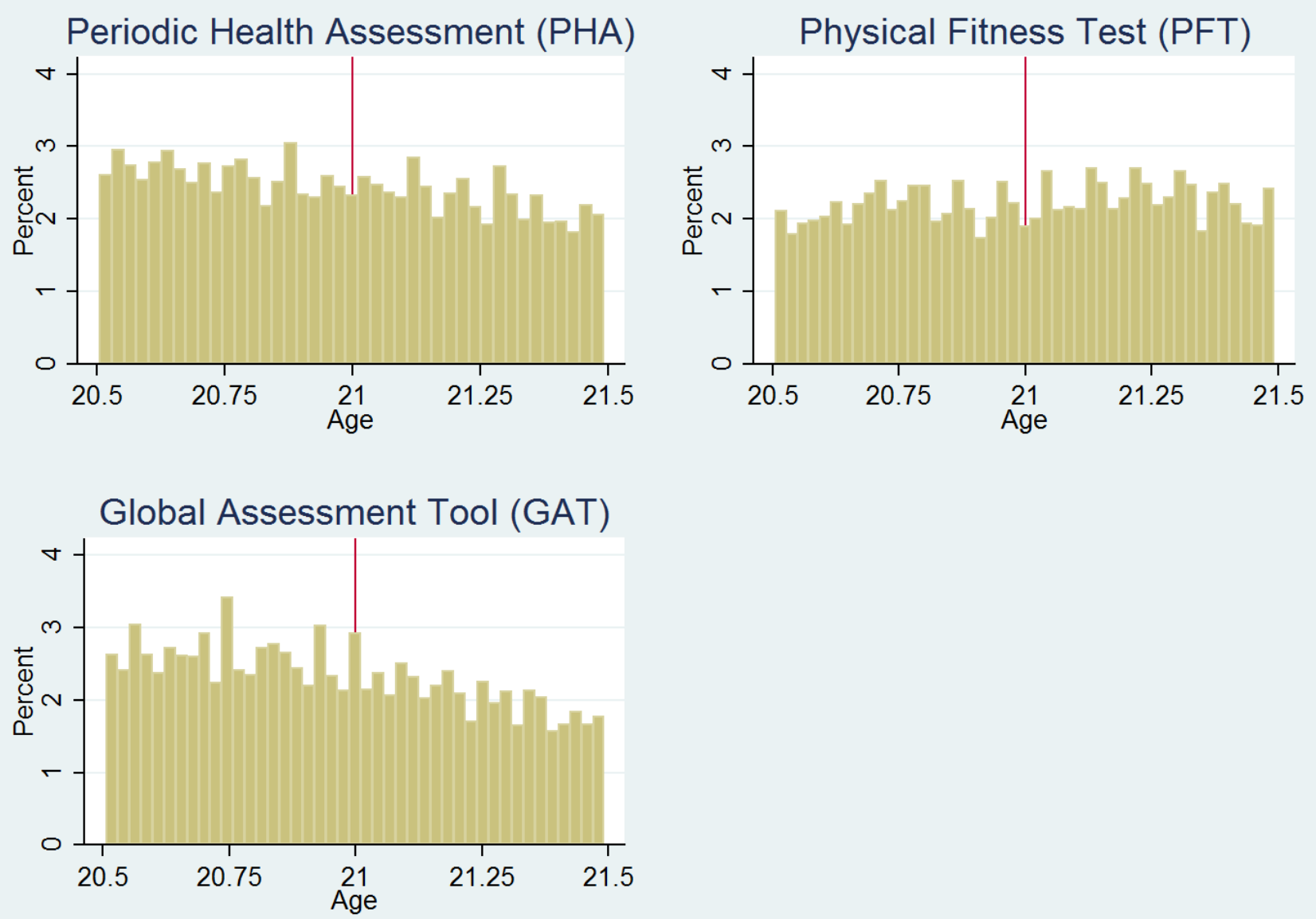

Notes: Datasets include all U.S. Army soldiers between the ages of 20.5 and 21.5 at any time between 2009 and 2015. Every U.S. Army soldier is required to take the PHA and GAT once per year, and the PFT twice per year. 
Figure 2: The impact of the MLDA on alcohol consumption amongst U.S. Army soldiers.
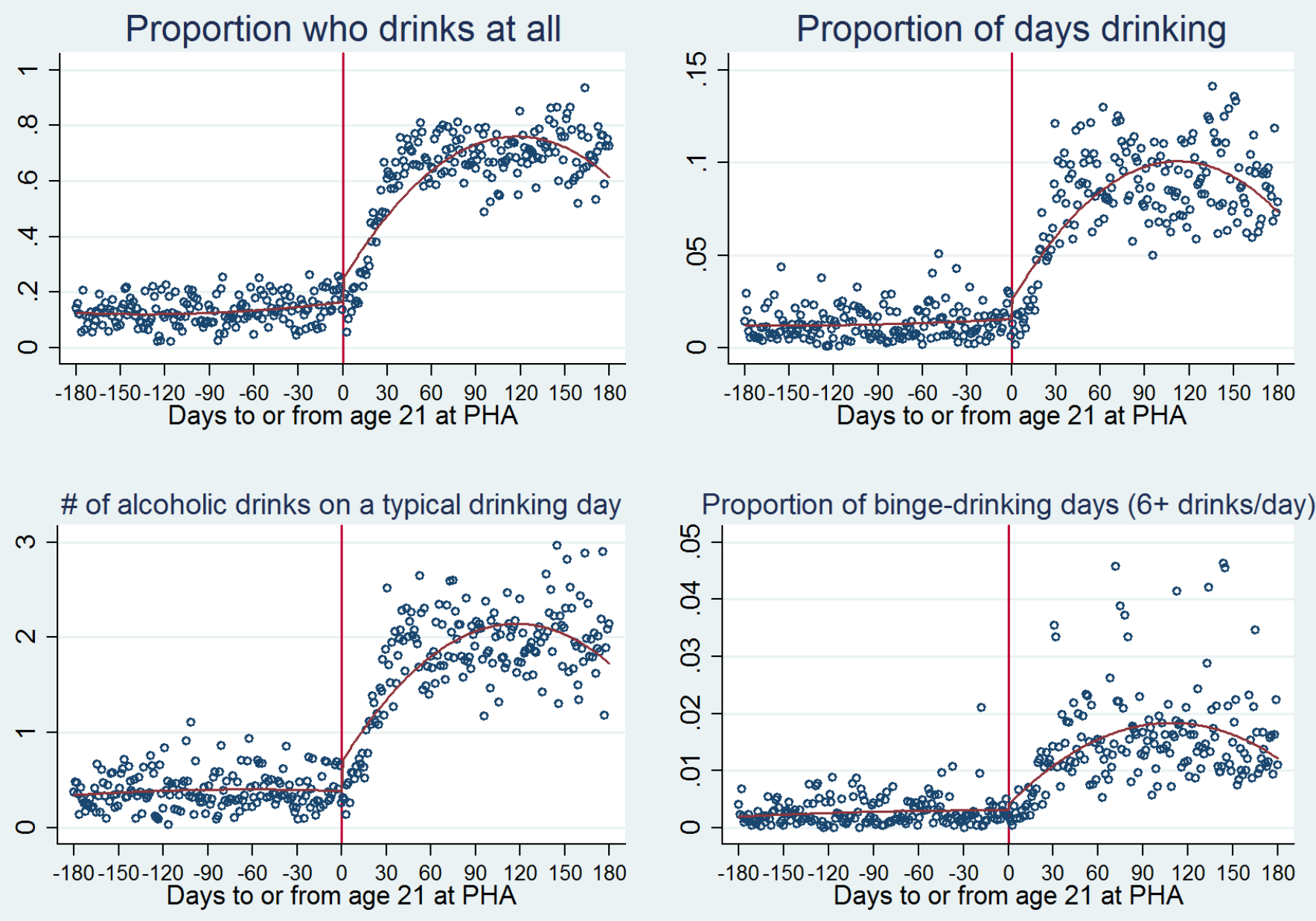

Notes: Data are self-reports from the Personal Health Assessments (PHA) of U.S. Army soldiers who were between the ages of 20.5 and 21.5 at any time between 2009 and 2015. Circles indicate the daily averages. The solid lines are separate fitted quadratic functions of age below and above age 21. See text for detailed definitions of the outcomes. 
Figure 3: The impacts of the MLDA on selected mental health, physical fitness, and job performance outcomes.
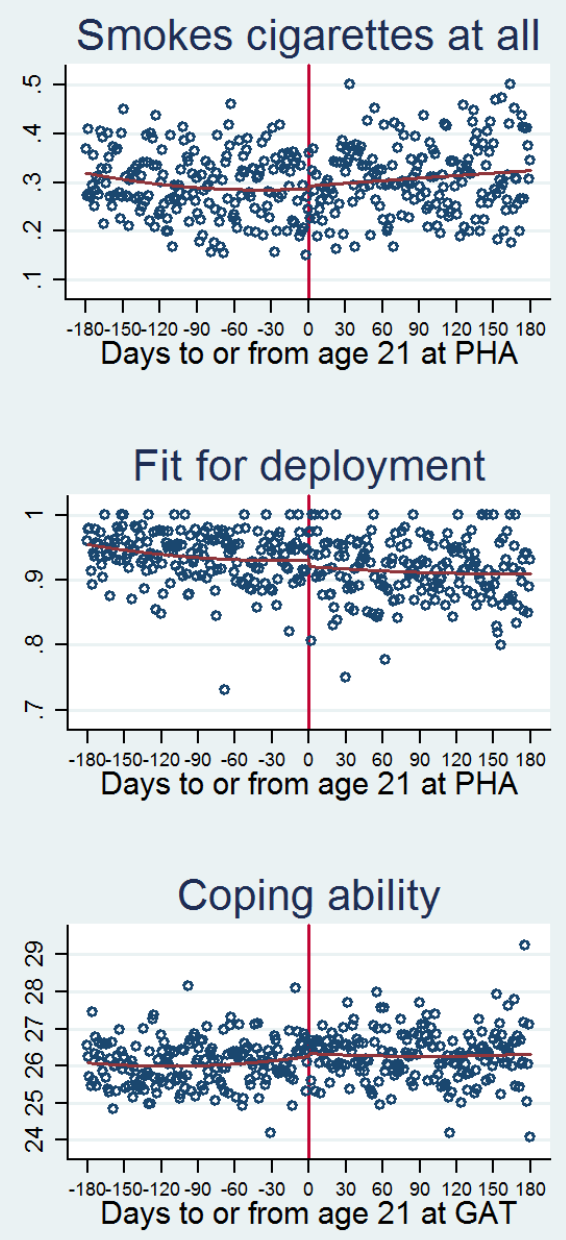

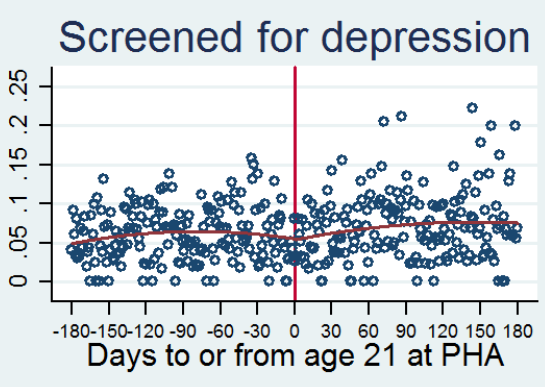

Total Physical Fitness Test score

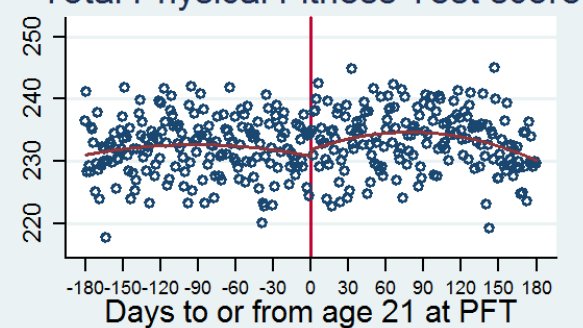

Any judicial or non-judicial offense

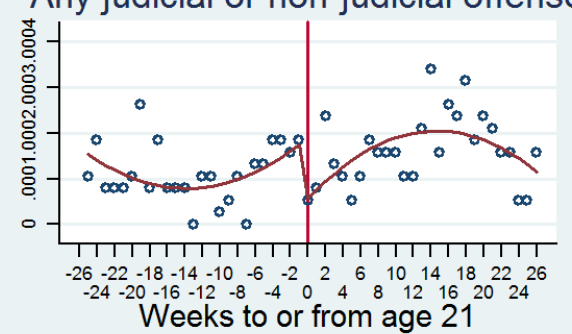

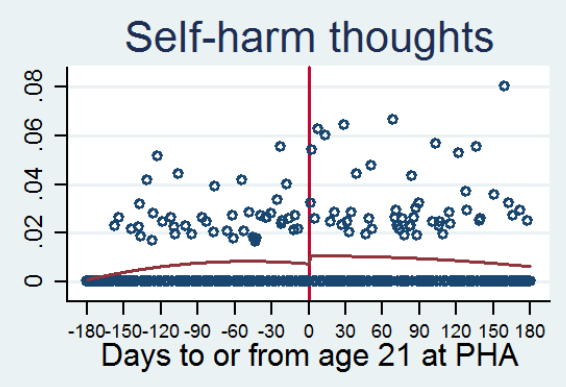

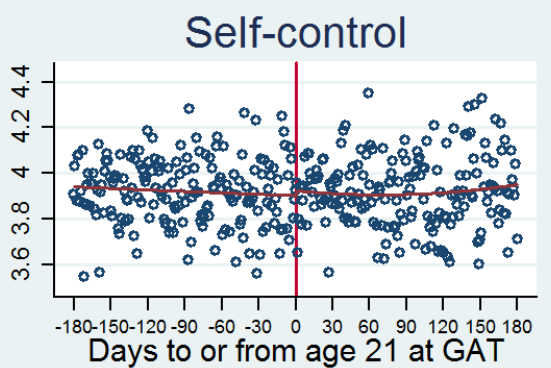

Days to or from age 21 at GAT

Notes: Circles indicate the daily averages. The solid lines are separate fitted quadratic functions of age below and above age 21. See text for definitions of the outcomes. 
Figure 4: Means of selected outcomes, by quartiles of self-control.
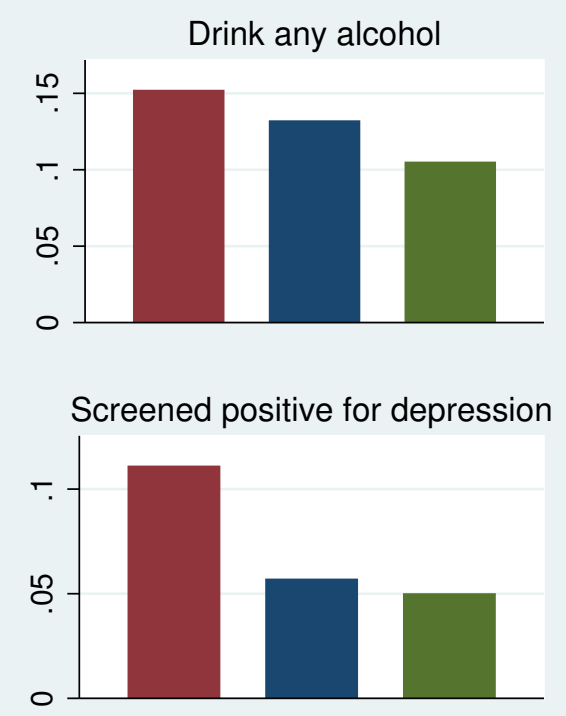

Total fitness score

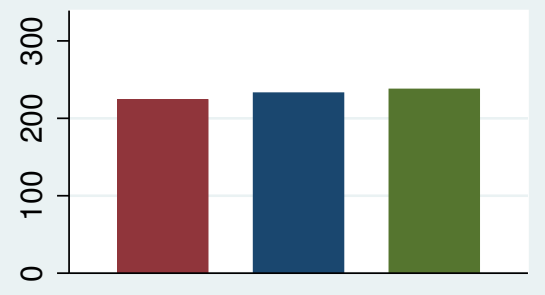

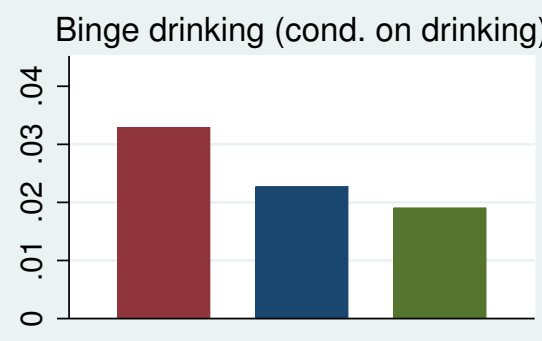

Self-harm (per 1,000)

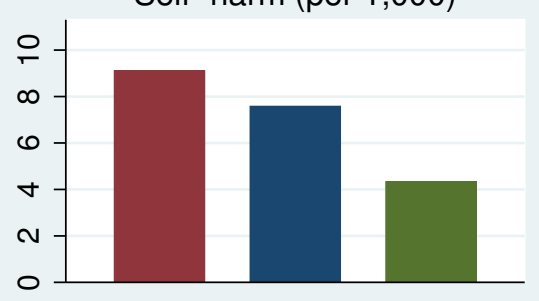

Committ offense (per 10,000)

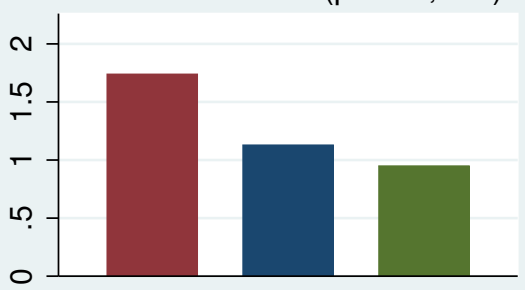

Smoker

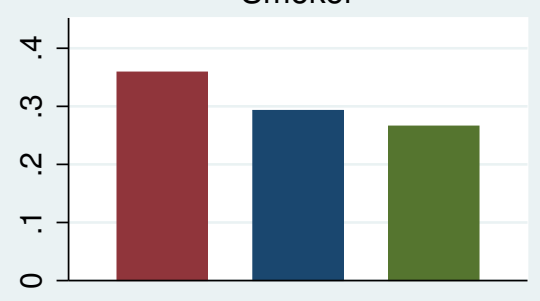

Fit for deployment

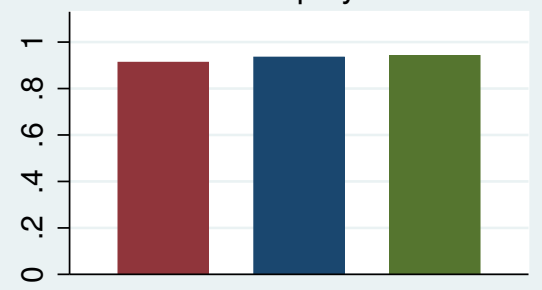

Notes: Samples include only observations for soldiers under 21 years old. See text for variable definitions. 
Figure 5: Means of selected outcomes, by quartiles of coping ability.

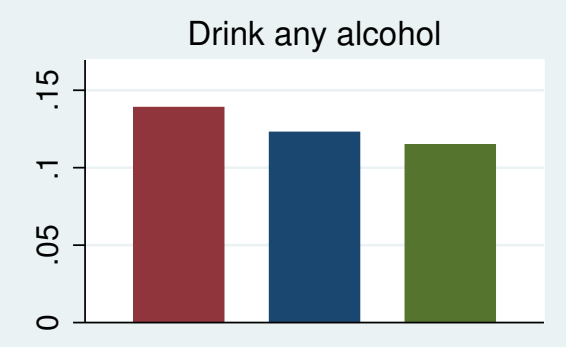

Screened positive for depression

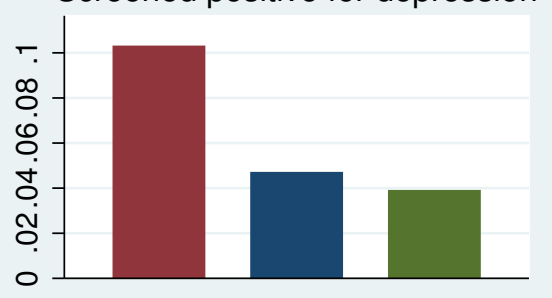

Total fitness score

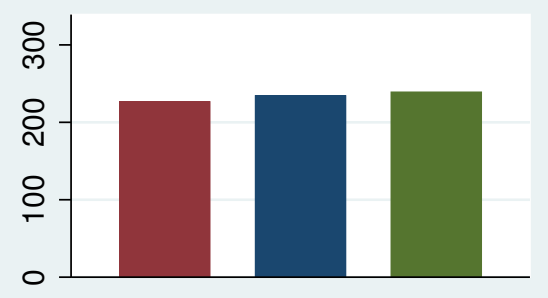

Binge drinking (cond. on drinking)

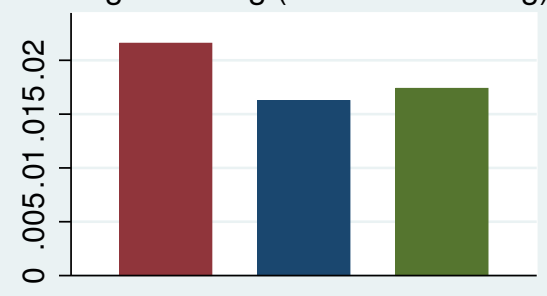

Self-harm (per 1,000)

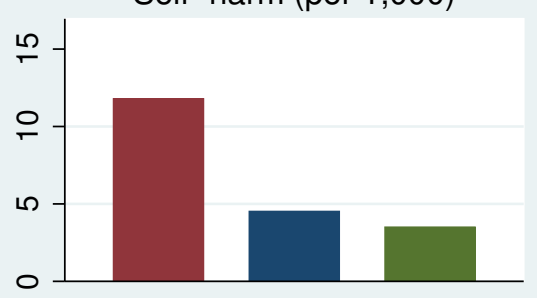

Committ offense (per 10,000)

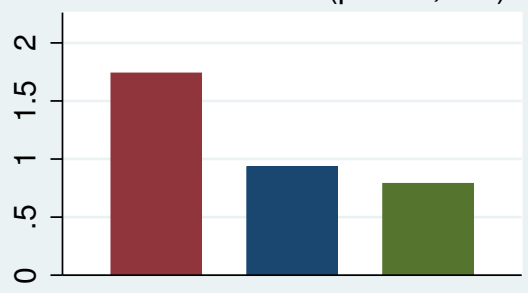

Smoker

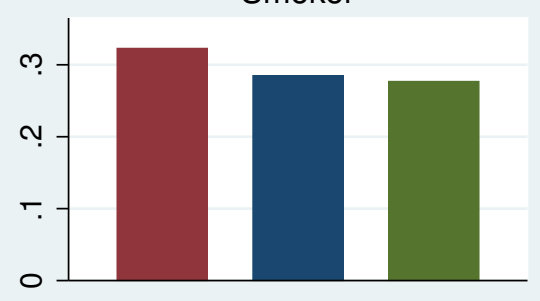

Fit for deployment

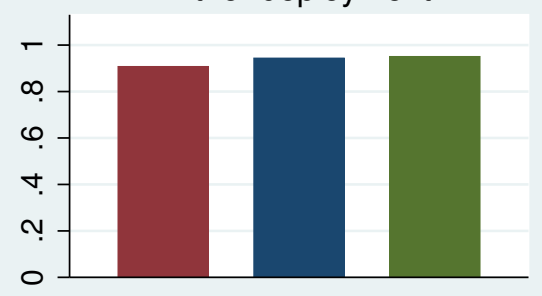

Notes: Samples include only observations for soldiers under 21 years old. See text for variable definitions. 
Figure 6: Means of selected outcomes, by quartiles of depression.

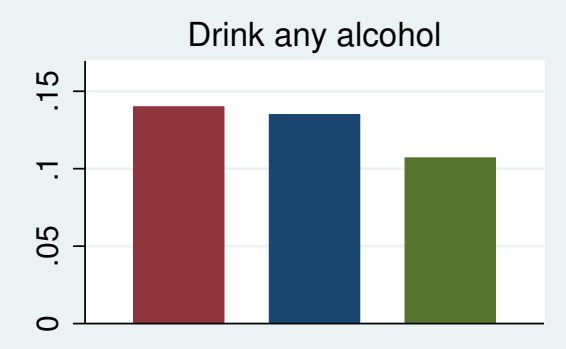

Screened positive for depression

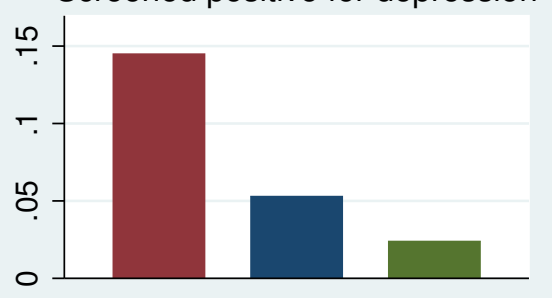

Total fitness score

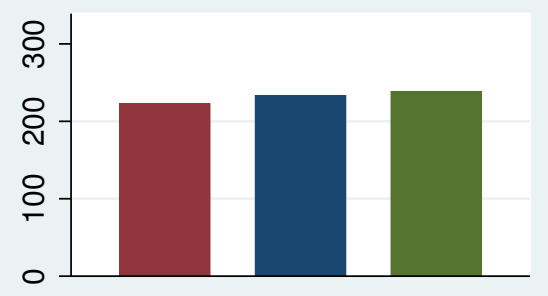

Binge drinking (cond. on drinking)

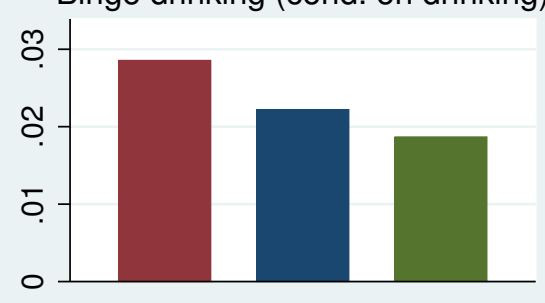

Self-harm (per 1,000)

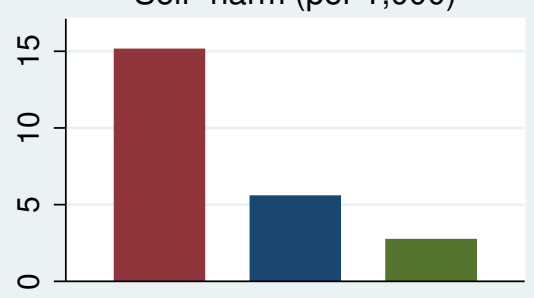

Committ offense (per 10,000)

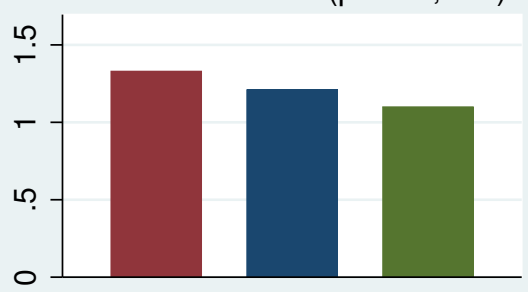

Smoker

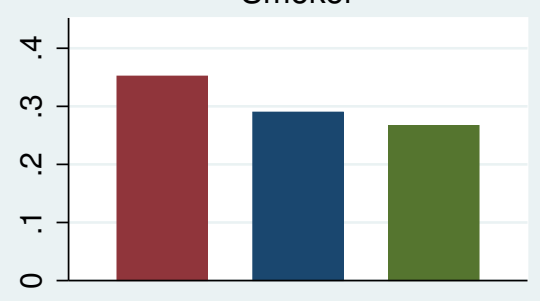

Fit for deployment

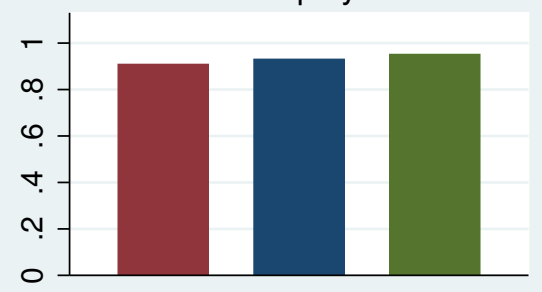

Notes: Samples include only observations for soldiers under 21 years old. See text for variable definitions. 
Figure 7: Means of selected outcomes, by quartiles of AFQT score.

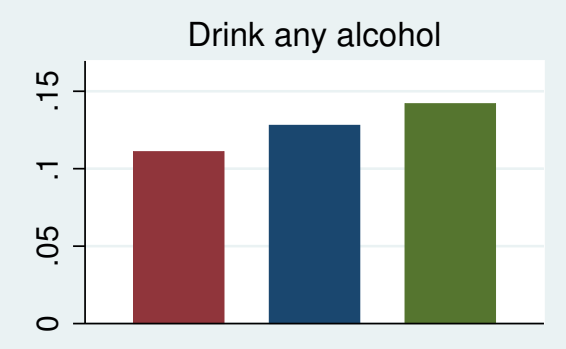

Screened positive for depression

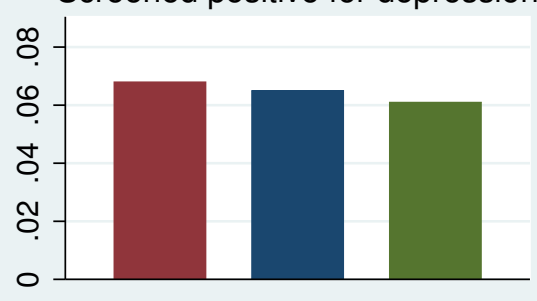

Total fitness score

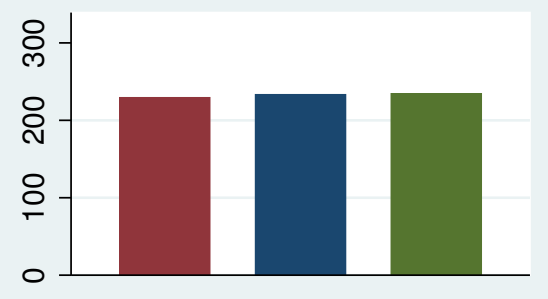

Binge drinking (cond. on drinking)

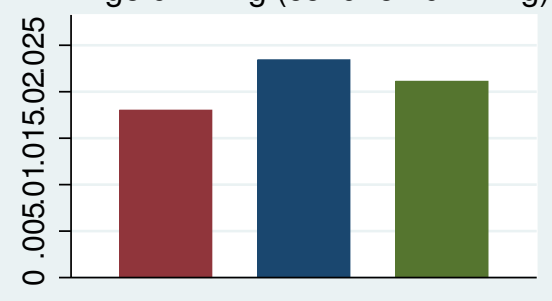

Self-harm (per 1,000)

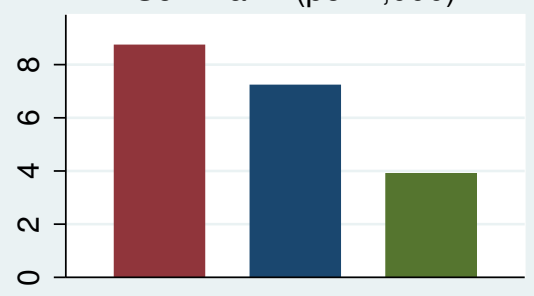

Committ offense (per 10,000)

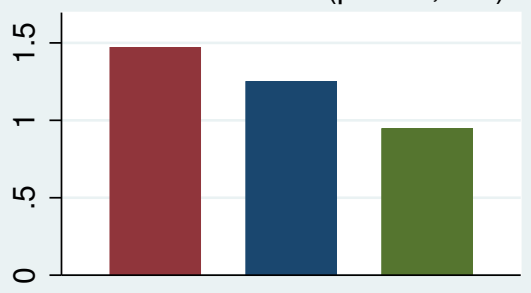

Smoker

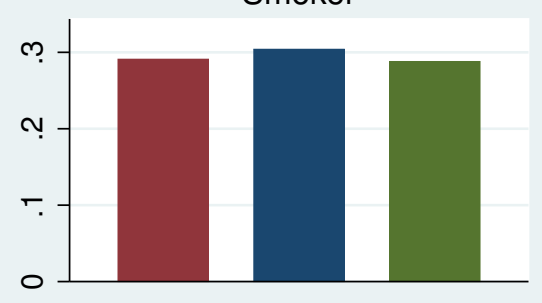

Fit for deployment

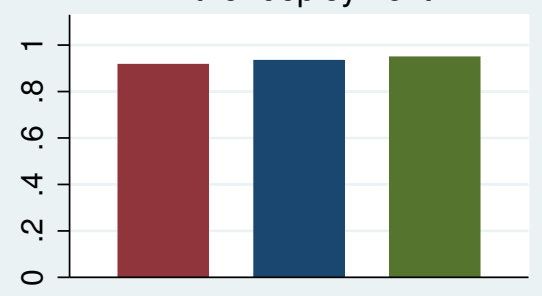

Notes:Samples include only observations for soldiers under 21 years old. See text for variable definitions. 
Figure 8: Means of selected outcomes, by any family history of mental health problems or chemical dependency.
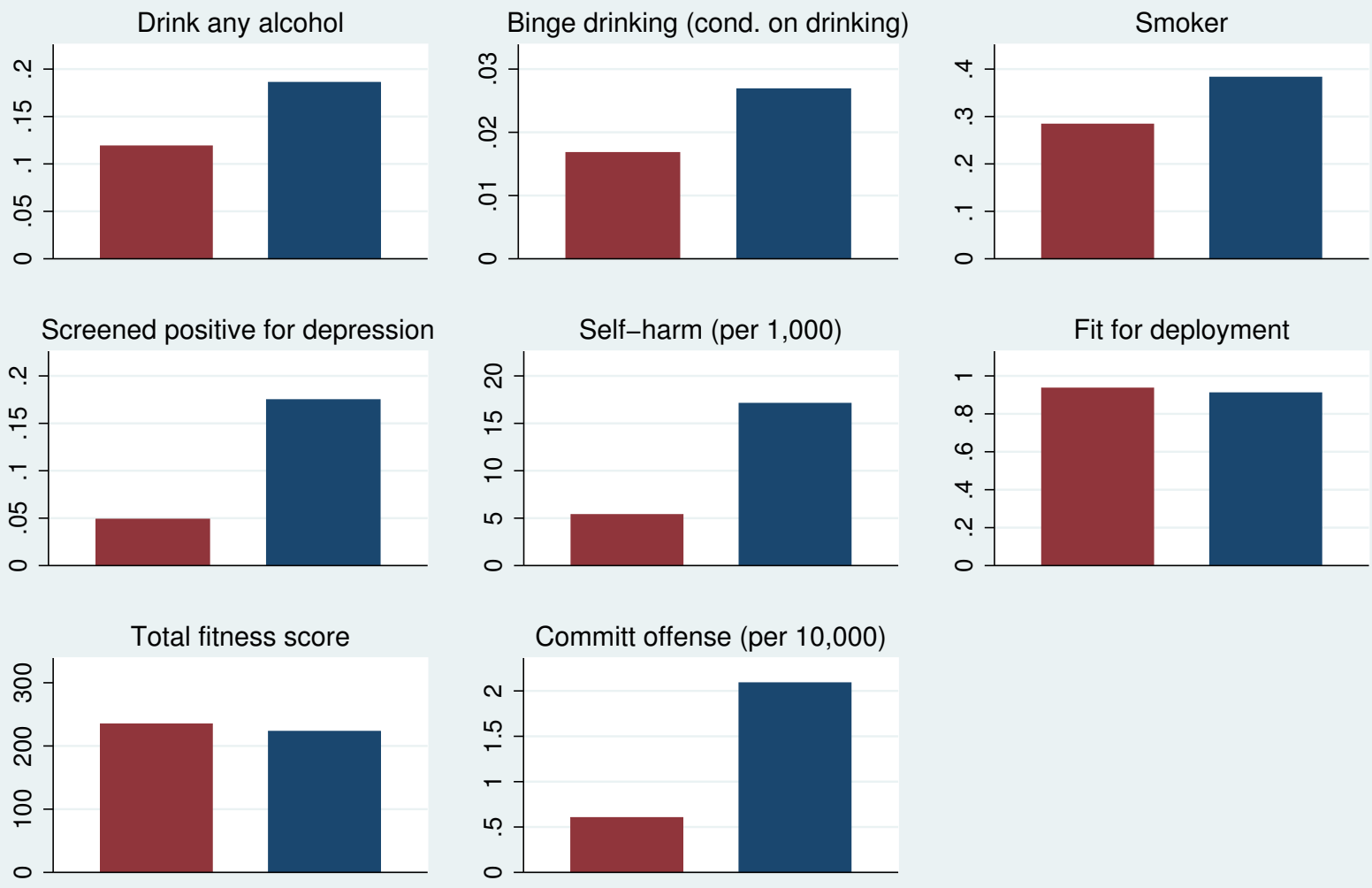

Notes: Samples include only observations for soldiers under 21 years old. See text for variable definitions. 
Table 1: Summary statistics of the population of soldiers aged 20.5 to 21.5 years old between 2009 and 2015.

\begin{tabular}{lccc}
\hline \hline & Mean & s.d. & Observations \\
\hline Age & 20.96 & 0.28 & 11,905 \\
Male & 0.828 & 0.377 & 11,905 \\
Completed high school & 0.987 & 0.115 & 11,905 \\
Armed Forces Qualifying Test (AFQT) score & 56.21 & 17.79 & 11,905 \\
White & 0.60 & 0.49 & 11,905 \\
Black & 0.219 & 0.413 & 11,905 \\
Asian & 0.036 & 0.187 & 11,905 \\
Hispanic & 0.136 & 0.343 & 11,905 \\
Other race & 0.010 & 0.099 & 11,905 \\
\hline
\end{tabular}

Notes: Sample includes all soldiers between 2009 and 2015 that were observed in the PHA at any time 180 days before or 180 days after their 21st birthday. 
Table 2: The impacts of the MLDA.

\begin{tabular}{|c|c|c|c|c|}
\hline Outcome & Over 21 & (s.e.) & Obs. & $\begin{array}{l}\text { Mean, under } \\
21 \text { sample }\end{array}$ \\
\hline \multicolumn{5}{|l|}{ Personal Health Assessment (PHA) sample } \\
\hline Drinks at all & $0.095 * * *$ & $(0.033)$ & 11,905 & 0.127 \\
\hline Proportion of drinking days & $0.012 * *$ & $(0.005)$ & 11,901 & 0.000 \\
\hline \# of alcoholic drinks on a typical drinking day & $0.334 * * *$ & $(0.107)$ & 11,903 & 0.376 \\
\hline Proportion of binge-drinking days ( $6+$ drinks per day) & 0.001 & $(0.002)$ & 11,905 & 0.003 \\
\hline Smokes cigarettes at all & 0.022 & $(0.024)$ & 11,905 & 0.297 \\
\hline Moderate to heavy smoker & 0.007 & $(0.014)$ & 11,905 & 0.079 \\
\hline Moderate to high nicotine dependency & 0.000 & $(0.010)$ & 11,905 & 0.041 \\
\hline Screened for depression & 0.007 & $(0.013)$ & 11,905 & 0.065 \\
\hline Self-harm thoughts & 0.006 & $(0.006)$ & 11,905 & 0.001 \\
\hline Fit for deployment & -0.008 & $(0.016)$ & 11,905 & 0.933 \\
\hline \multicolumn{5}{|l|}{ Global Assessment Tool (GAT) sample } \\
\hline Coping ability & 0.025 & (0.059) & 15,321 & 3.92 \\
\hline Self-control & 0.044 & $(0.236)$ & 15,321 & 26.06 \\
\hline \multicolumn{5}{|l|}{ Physical Fitness Test (PFT) sample } \\
\hline Total PFT score & 1.02 & (1.59) & 28,998 & 232.60 \\
\hline Push-up score & 0.38 & $(0.52)$ & 28,998 & 83.74 \\
\hline Sit-up score & 0.09 & $(0.64)$ & 28,998 & 79.59 \\
\hline 2-mile run score & 0.56 & $(0.87)$ & 28,998 & 69.30 \\
\hline \multicolumn{5}{|l|}{ Non-Judicial and Judicial Punishment sample } \\
\hline Any offense & $-0.0001 * *$ & $(0.0001)$ & $1,525,108$ & 0.000123 \\
\hline Level 1 offense (letter of reprimand) & $-0.0001 * * *$ & $(0.0000)$ & $1,525,108$ & 0.0000723 \\
\hline Level 2 offense (Article 15 proceedings) & 0.0000 & $(0.0000)$ & $1,525,108$ & 0.0000273 \\
\hline Level 3 offense (court martial) & 0.0000 & $(0.0000)$ & $1,525,108$ & 0.0000232 \\
\hline
\end{tabular}

Notes: ${ }^{* *} \mathrm{p}<0.01, * * \mathrm{p}<0.05, * \mathrm{p}<0.1$ Each row constitutes a separate regression estimated with quadratic terms in age and a range of 180 days on each side of the 21st birthday. Robust standard errors are clustered at the day (age) level. Covariates include AFQT score and indicators for gender, education level, and race/ethnicity. 


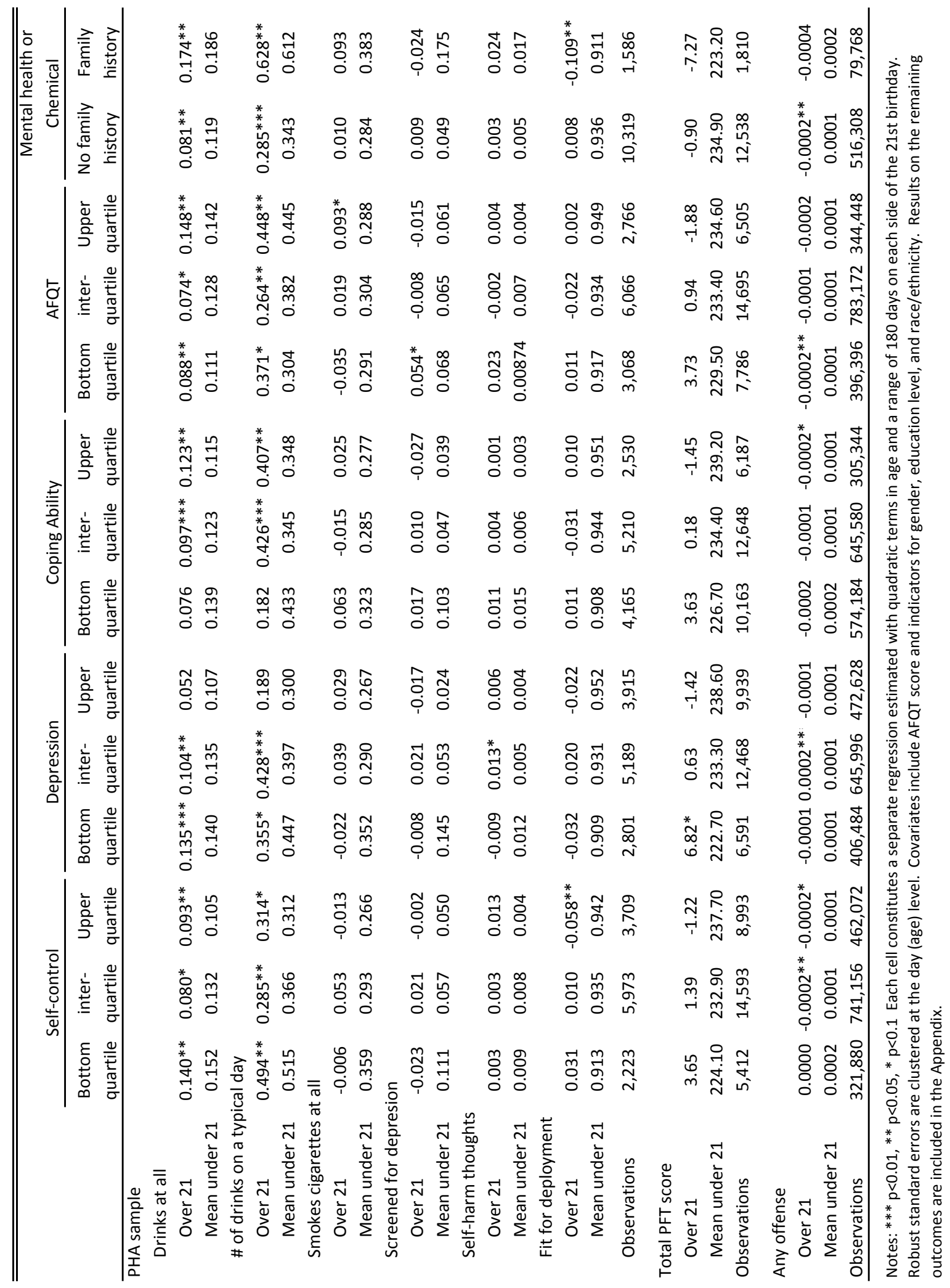


Appendix Table 1: Tests of the balance of covariates across the MLDA discontinuity.

\begin{tabular}{|c|c|c|c|c|}
\hline Outcome & Over 21 & (s.e.) & Obs. & $\begin{array}{l}\text { Mean, under } \\
21 \text { sample }\end{array}$ \\
\hline \multicolumn{5}{|c|}{ Personal Health Assessment (PHA) sample } \\
\hline Female & $0.055 * * *$ & $(0.020)$ & 11,905 & 0.159 \\
\hline AFQT score & 0.347 & $(0.826)$ & 11,905 & 56.250 \\
\hline High School only & 0.000 & $(0.006)$ & 11,905 & 0.985 \\
\hline Completed college & -0.001 & $(0.005)$ & 11,905 & 0.011 \\
\hline Black & -0.017 & $(0.022)$ & 11,905 & 0.212 \\
\hline Hispanic & -0.020 & $(0.015)$ & 11,905 & 0.139 \\
\hline Asian & 0.001 & $(0.009)$ & 11,905 & 0.038 \\
\hline Other race & 0.004 & $(0.006)$ & 11,905 & 0.010 \\
\hline \multicolumn{5}{|c|}{ Physical Fitness Test (PFT) sample } \\
\hline Female & -0.005 & $(0.010)$ & 28,998 & 0.137 \\
\hline AFQT score & -0.225 & $(0.654)$ & 28,998 & 55.470 \\
\hline High School only & 0.002 & $(0.004)$ & 28,998 & 0.988 \\
\hline Completed college & -0.003 & $(0.003)$ & 28,998 & 0.009 \\
\hline Black & $-0.023 *$ & $(0.013)$ & 28,998 & 0.216 \\
\hline Hispanic & 0.007 & $(0.012)$ & 28,998 & 0.136 \\
\hline Asian & $0.011^{*}$ & $(0.006)$ & 28,998 & 0.036 \\
\hline Other race & 0.002 & $(0.004)$ & 28,998 & 0.010 \\
\hline \multicolumn{5}{|c|}{ Global Assessment Tool (GAT) sample } \\
\hline Female & -0.017 & $(0.015)$ & 15,321 & 0.159 \\
\hline AFQT score & 0.307 & $(0.764)$ & 15,321 & 55.860 \\
\hline High School only & 0.000 & $(0.005)$ & 15,321 & 0.985 \\
\hline Completed college & -0.002 & $(0.004)$ & 15,321 & 0.012 \\
\hline Black & -0.021 & $(0.015)$ & 15,321 & 0.201 \\
\hline Hispanic & -0.014 & $(0.014)$ & 15,321 & 0.127 \\
\hline Asian & 0.005 & $(0.008)$ & 15,321 & 0.033 \\
\hline Other race & 0.002 & $(0.004)$ & 15,321 & 0.010 \\
\hline \multicolumn{5}{|c|}{ Non-Judicial and Judicial Punishment sample } \\
\hline Female & 0.000 & $(0.000)$ & $1,530,000$ & 0.161 \\
\hline AFQT score & 0.000 & $(0.000)$ & $1,530,000$ & 55.110 \\
\hline High School only & 0.000 & $(0.000)$ & $1,530,000$ & 0.984 \\
\hline Completed college & 0.000 & $(0.000)$ & $1,530,000$ & 0.011 \\
\hline Black & 0.000 & $(0.000)$ & $1,530,000$ & 0.198 \\
\hline Hispanic & 0.000 & $(0.000)$ & $1,530,000$ & 0.128 \\
\hline Asian & 0.000 & $(0.000)$ & $1,530,000$ & 0.032 \\
\hline Other race & 0.000 & $(0.000)$ & $1,530,000$ & 0.011 \\
\hline
\end{tabular}

Notes: ${ }^{* *} p<0.01, * * p<0.05, * p<0.1$ Each row constitutes a separate regression estimated with quadratic terms in age and a range of 180 days on each side of the 21st birthday. Robust standard errors are clustered at the day (age) level. Covariates include AFQT score and indicators for gender, education level, and race/ethnicity. 
Appendix Table 2: Robustness of the RD estimates, PHA sample outcomes.

\begin{tabular}{|c|c|c|c|c|c|c|}
\hline Order of polynomial in age & 1 & 2 & 3 & 1 & 2 & 3 \\
\hline Covariates? & No & No & No & Yes & Yes & Yes \\
\hline \multicolumn{7}{|l|}{ Drinks at all } \\
\hline Over 21 & $0.296 * * *$ & $0.095 * * *$ & $-0.093 * *$ & $0.297 * * *$ & $0.098 * * *$ & $-0.087^{* *}$ \\
\hline [s.e] & {$[0.030]$} & [0.033] & [0.031] & [0.030] & [0.033] & [0.031] \\
\hline $\mathrm{p}$-value & 1.00 & 1.00 & 0.91 & 1.00 & 0.98 & 0.00 \\
\hline \multicolumn{7}{|l|}{ Proportion of drinking days } \\
\hline Over 21 & $0.042^{* * *}$ & $0.012^{* *}$ & -0.014 & $0.043 * * *$ & $0.013^{* *}$ & $-0.012^{* *}$ \\
\hline [s.e] & [0.005] & {$[0.005]$} & [0.005] & [0.005] & [0.005] & [0.005] \\
\hline$p$-value & 1.00 & 0.99 & 0.70 & 1.00 & 0.19 & 0.00 \\
\hline \multicolumn{7}{|c|}{ \# of drinks on a typical drinking day } \\
\hline Over 21 & $0.835^{* * *}$ & $0.334^{* * *}$ & $-0.212 * *$ & $0.847^{* * *}$ & $0.356^{* * *}$ & $-0.173^{*}$ \\
\hline [s.e] & [0.096] & [0.107] & [0.103] & [0.095] & {$[0.106]$} & [0.104] \\
\hline$p$-value & 1.00 & 1.00 & 1.00 & 0.97 & 0.00 & 0.00 \\
\hline \multicolumn{7}{|c|}{ Proportion of binge-drinking days } \\
\hline Over 21 & $0.007^{* * *}$ & 0.001 & -0.003 & $0.007 * * *$ & 0.002 & -0.002 \\
\hline [s.e] & [0.001] & {$[0.002]$} & [0.002] & [0.001] & [0.002] & {$[0.002]$} \\
\hline$p$-value & 0.76 & 0.44 & 0.31 & 0.12 & 0.02 & 0.01 \\
\hline \multicolumn{7}{|l|}{ Smokes cigarettes at all } \\
\hline Over 21 & 0.021 & 0.022 & 0.004 & 0.023 & 0.026 & 0.014 \\
\hline [s.e] & [0.016] & [0.024] & [0.033] & [0.016] & [0.024] & [0.032] \\
\hline$p$-value & 0.27 & 0.28 & 0.26 & 0.00 & 0.00 & 0.00 \\
\hline \multicolumn{7}{|l|}{ Moderate to heavy smoker } \\
\hline Over 21 & 0.011 & 0.007 & 0.000 & 0.012 & 0.006 & 0.002 \\
\hline [s.e] & [0.009] & [0.014] & [0.018] & [0.009] & [0.014] & [0.018] \\
\hline$p$-value & 0.38 & 0.41 & 0.43 & 0.00 & 0.00 & 0.00 \\
\hline \multicolumn{7}{|c|}{ Moderate/high nictoine dependency } \\
\hline Over 21 & -0.001 & 0.000 & -0.007 & -0.001 & -0.001 & -0.006 \\
\hline [s.e] & [0.007] & [0.010] & [0.014] & {$[0.007]$} & [0.010] & [0.014] \\
\hline$p$-value & 0.38 & 0.41 & 0.43 & 0.00 & 0.00 & 0.00 \\
\hline \multicolumn{7}{|l|}{ Screened for depression } \\
\hline Over 21 & -0.004 & 0.007 & -0.009 & -0.006 & 0.004 & -0.012 \\
\hline [s.e] & {$[0.009]$} & [0.013] & {$[0.016]$} & {$[0.009]$} & {$[0.013]$} & {$[0.016]$} \\
\hline$p$-value & 0.71 & 0.71 & 0.70 & 0.25 & 0.25 & 0.24 \\
\hline \multicolumn{7}{|l|}{ Self-harm thoughts } \\
\hline Over 21 & 0.002 & 0.006 & 0.009 & 0.002 & 0.006 & 0.008 \\
\hline [s.e] & [0.004] & {$[0.006]$} & {$[0.008]$} & {$[0.004]$} & {$[0.006]$} & {$[0.008]$} \\
\hline$p$-value & 0.82 & 0.82 & 0.81 & 0.78 & 0.79 & 0.78 \\
\hline \multicolumn{7}{|l|}{ Fit for deployment } \\
\hline Over 21 & -0.009 & -0.008 & 0.000 & -0.003 & 0.004 & 0.017 \\
\hline [s.e] & [0.011] & [0.016] & {$[0.022]$} & {$[0.011]$} & {$[0.016]$} & {$[0.021]$} \\
\hline $\mathrm{p}$-value & 0.69 & 0.69 & 0.67 & 0.00 & 0.00 & 0.00 \\
\hline Observations & 11,905 & 11,905 & 11,905 & 11,905 & 11,905 & 11,905 \\
\hline
\end{tabular}

Notes: *** $p<0.01, * * p<0.05, * p<0.1$ Each row constitutes a separate regression estimated with quadratic terms in age and a range of 180 days on each side of the 21st birthday. Robust standard errors are clustered at the day (age) level. The $p$-value is from a test of whether the non-parametric model is equal to the parametric model; see text for details.

Covariates include AFQT score and indicators for gender, education level, and race/ethnicity. 
Appendix Table 3: Robustness of the RD estimates, GAT and PFT samples outcomes.

\begin{tabular}{|c|c|c|c|c|c|c|}
\hline Order of polynomial in age & 1 & 2 & 3 & 1 & 2 & 3 \\
\hline Covariates? & No & No & No & Yes & Yes & Yes \\
\hline \multicolumn{7}{|c|}{ Global Assessment Tool (GAT) sample } \\
\hline \multicolumn{7}{|l|}{ Coping ability } \\
\hline Over 21 & -0.048 & 0.025 & -0.068 & -0.050 & 0.024 & -0.073 \\
\hline [s.e] & [0.039] & [0.059] & {$[0.076]$} & [0.039] & [0.059] & {$[0.076]$} \\
\hline $\mathrm{p}$-value & 0.80 & 0.79 & 0.78 & 0.03 & 0.02 & 0.02 \\
\hline \multicolumn{7}{|l|}{ Self-control } \\
\hline Over 21 & 0.0396 & 0.0441 & -0.1311 & 0.0186 & 0.0137 & -0.1792 \\
\hline [s.e] & {$[0.165]$} & {$[0.236]$} & [0.318] & [0.166] & {$[0.238]$} & [0.323] \\
\hline$p$-value & 0.85 & 0.85 & 0.86 & 0.03 & 0.03 & 0.03 \\
\hline Observations & 15,321 & 15,321 & 15,321 & 15,315 & 15,315 & 15,315 \\
\hline \multicolumn{7}{|c|}{ Physical Fitness Test (PFT) sample } \\
\hline \multicolumn{7}{|c|}{ Total PFT score } \\
\hline Over 21 & $2.20 * *$ & 1.02 & 1.37 & $2.11 * *$ & 0.94 & 1.28 \\
\hline [s.e] & {$[1.06]$} & {$[1.59]$} & {$[2.02]$} & {$[1.06]$} & {$[1.60]$} & {$[2.04]$} \\
\hline $\mathrm{p}$-value & 0.63 & 0.53 & 0.50 & 0.00 & 0.00 & 0.00 \\
\hline \multicolumn{7}{|l|}{ Push-up score } \\
\hline Over 21 & $0.64 *$ & 0.38 & 0.59 & $0.61^{*}$ & 0.33 & 0.53 \\
\hline [s.e] & {$[0.35]$} & {$[0.52]$} & {$[0.65]$} & {$[0.35]$} & {$[0.52]$} & {$[0.65]$} \\
\hline $\mathrm{p}$-value & 0.91 & 0.88 & 0.86 & 0.00 & 0.00 & 0.00 \\
\hline \multicolumn{7}{|l|}{ Sit-up score } \\
\hline Over 21 & $0.77^{*}$ & 0.09 & 0.47 & $0.75^{*}$ & 0.09 & 0.45 \\
\hline [s.e] & {$[0.42]$} & {$[0.64]$} & {$[0.86]$} & {$[0.41]$} & {$[0.64]$} & {$[0.86]$} \\
\hline $\mathrm{p}$-value & 0.97 & 0.96 & 0.96 & 0.85 & 0.90 & 0.93 \\
\hline \multicolumn{7}{|l|}{ 2-mile run score } \\
\hline Over 21 & 0.79 & 0.56 & 0.31 & 0.75 & 0.52 & 0.29 \\
\hline [s.e] & {$[0.57]$} & [0.87] & [1.11] & {$[0.57]$} & {$[0.87]$} & [1.11] \\
\hline$p$-value & 0.43 & 0.37 & 0.36 & 0.00 & 0.00 & 0.00 \\
\hline Observations & 28,998 & 28,998 & 28,998 & 28,986 & 28,986 & 28,986 \\
\hline
\end{tabular}

Notes: $* * * p<0.01, * * p<0.05, * p<0.1$ Each row constitutes a separate regression estimated with quadratic terms in age and a range of 180 days on each side of the 21st birthday. Robust standard errors are clustered at the day (age) level. Covariates include AFQT score and indicators for gender, education level, and race/ethnicity. 
Appendix Table 4: Robustness of the RD estimates, IPERMS sample outcomes.

\begin{tabular}{|c|c|c|c|c|c|c|}
\hline Order of polynomial in age & 1 & 2 & 3 & 1 & 2 & 3 \\
\hline Covariates? & No & No & No & Yes & Yes & Yes \\
\hline \multicolumn{7}{|c|}{ Non-Judicial and Judicial Punishment sample } \\
\hline \multicolumn{7}{|l|}{ Any offense } \\
\hline Over 21 & 0.0000 & $-0.0001 * *$ & -0.0001 & 0.0000 & $-0.0001 * *$ & -0.0001 \\
\hline [s.e] & {$[0.0000]$} & {$[0.0001]$} & {$[0.0001]$} & {$[0.0000]$} & {$[0.0001]$} & {$[0.0001]$} \\
\hline$p$-value & 0.99 & 0.90 & 0.59 & 0.78 & 0.14 & 0.00 \\
\hline \multicolumn{7}{|c|}{ Level 1 offense (letter of reprimand) } \\
\hline Over 21 & 0.0000 & $-0.0001 * * *$ & $-0.0001 * *$ & 0.0000 & $-0.0001 * *$ & $-0.0001 * *$ \\
\hline [s.e] & {$[0.0000]$} & {$[0.0000]$} & {$[0.0000]$} & {$[0.0000]$} & {$[0.0000]$} & {$[0.0000]$} \\
\hline p-value & 0.90 & 0.62 & 0.15 & 0.57 & 0.13 & 0.00 \\
\hline \multicolumn{7}{|c|}{ Level 2 offense (Article 15 proceedings) } \\
\hline Over 21 & 0.0000 & 0.0000 & 0.0000 & 0.0000 & 0.0000 & 0.0000 \\
\hline [s.e] & {$[0.0000]$} & {$[0.0000]$} & {$[0.0000]$} & {$[0.0000]$} & {$[0.0000]$} & {$[0.0000]$} \\
\hline p-value & 0.46 & 0.42 & 0.50 & 0.52 & 0.48 & 0.52 \\
\hline \multicolumn{7}{|c|}{ Level 3 offense (court martial) } \\
\hline Over 21 & $0.0000 *$ & 0.0000 & 0.0000 & $0.0000 *$ & 0.0000 & 0.0000 \\
\hline [s.e] & {$[0.0000]$} & {$[0.0000]$} & {$[0.0000]$} & {$[0.0000]$} & {$[0.0000]$} & {$[0.0000]$} \\
\hline$p$-value & 0.46 & 0.40 & 0.36 & 0.05 & 0.03 & 0.02 \\
\hline Observations & $1,525,108$ & $1,525,108$ & $1,525,108$ & $1,524,016$ & $1,524,016$ & $1,524,015$ \\
\hline
\end{tabular}

Notes: ${ }^{* * *} p<0.01,{ }^{* *} p<0.05,{ }^{*} p<0.1$ Each row constitutes a separate regression estimated with quadratic terms in age and a range of 180 days on each side of the 21st birthday. Robust standard errors are clustered at the day (age) level. Covaritaes include AFQT score and indicators for gender, education level, and race/ethnicity. 


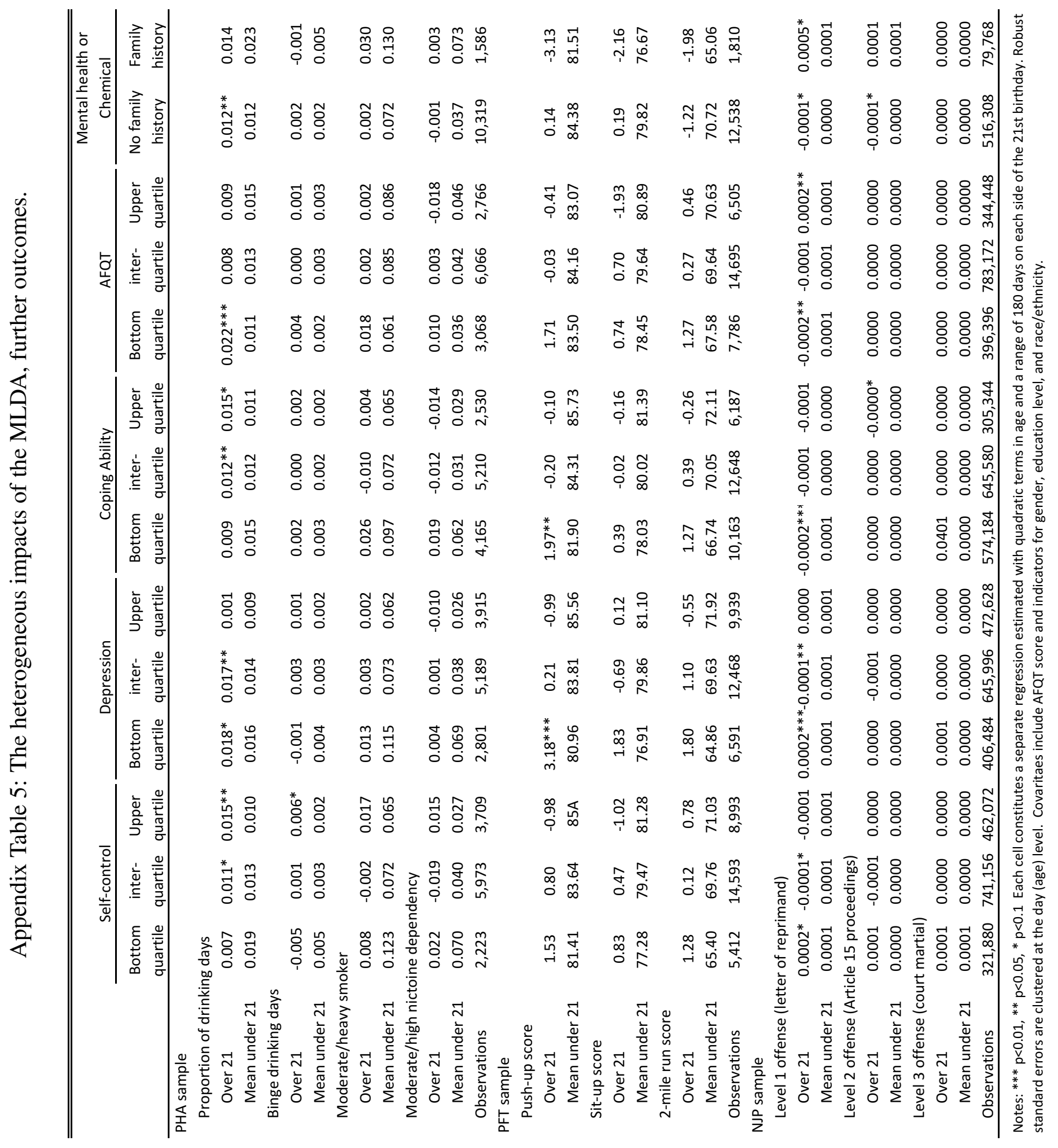

